\title{
Regional disparities and seasonal differences in climate risk to rice labour
}

Authors:

1. *Charles Simpson (a) ORCID: 0000-0001-9356-5833

2. J. Scott Hosking (a, b) ORCID: 0000-0002-3646-3504

3. Dann Mitchell (c) ORCID: 0000-0002-0117-3486

4. Richard A. Betts (d,e) ORCID: 0000-0002-4929-0307

5. Emily Shuckburgh (f) ORCID: 0000-0001-9206-3444

Correspondence:champs@bas.ac.uk

Affiliations and Addresses:

a) British Antarctic Survey, High Cross, Cambridge, CB3 OET, United Kingdom

b) The Alan Turing Institute, 96 Euston Rd, Somers Town, London NW1 2DB, United Kingdom

c) University of Bristol, University Road, Clifton, Bristol BS8 1SS, United Kingdom

d) Met Office Hadley Centre, FitzRoy Road, Exeter, EX1 3PB

e) University of Exeter Global Systems Institute, Laver Building, North Park Road, Exeter, EX4 4QE, United Kingdom

f) Department of Computer Science and Technology, University of Cambridge, JJ Thomson Ave, Cambridge CB3 OFD, United Kingdom

This document is a preprint submitted to EarthArXiv, it has not been peer reviewed.

This is version 2 of this manuscript. Version 1 was titled Regional disparities in climate risk to rice labour and food security. 


\section{Abstract}

The 880 million agricultural workers of the world are especially vulnerable to increasing heat stress due to climate change, affecting the health and income of individuals, while also decreasing global economic productivity. In this study, we focus on rice harvests across Asia and estimate the future impact on labour productivity by considering changes in climate at the time of the annual harvest. During these specific times of the year, heat stress is often high compared to the rest of the year. Examining climate simulations of the Coupled Model Intercomparison Project 6 (CMIP6), we identified that labour productivity metrics for the rice harvest, based on local wet-bulb globe temperature, are strongly correlated with global mean near-surface air temperature in the long term ( $p<<0.01, R^{2}>0.98$ in all models). Limiting global warming to $1.5^{\circ} \mathrm{C}$ rather than $2.0^{\circ} \mathrm{C}$ prevents a clear reduction in labour capacity of $1 \%$ across all Asia and $2 \%$ across Southeast Asia, affecting the livelihoods of around 100 million people. Due to differences in mechanization between and within countries, we find that rice labour is especially vulnerable in Indonesia, the Philippines, Bangladesh, and the Indian states of West Bengal and Kerala. Our results highlight the regional disparities and importance in considering seasonal differences in the estimation of the effect of climate change on labour productivity and occupational heat-stress. 


\section{Introduction}

Agricultural workers are especially vulnerable to hot and humid weather, which impacts health and productivity. There are 880 million agricultural workers worldwide (2019 estimate) ${ }^{1}$, the majority in lowincome countries (LIC) and lower-middle income countries (LMIC). Field studies have demonstrated the presence of heat strain and related health issues in agricultural workers ${ }^{2-4}$. Many workers are subject to high seasonal temperatures that, despite not being extreme statistically, can be harmful. Workers self-pace to cope with heat strain, so changes in labour productivity are a proxy for welfare, as well as being an indication of economic impact. People in the tropics, and outdoor workers especially, will be exposed more frequently to hot and humid conditions in the future due to climate change $\mathrm{e}^{5-7}$.

Ninety percent of global rice production is in Asia, equivalent to 630 million tonnes per year (in $2010-2012)^{8,9}$. The majority of rice cropland is tropical or subtropical (57\% between $23.45 \mathrm{deg} \mathrm{N}$ and S, $95 \%$ between 35 deg $\mathrm{N}$ and S), see Figure 1. In the Asia and Pacific region, agriculture employs more than 580 million people (2019 estimate) ${ }^{1}$, and rice production comprises $20 \%$ of total crop gross production value (2018 estimate $)^{10}$. The labour of rice production is not evenly distributed through the year, and in some locations rice is harvested during the hottest months of the year ${ }^{4}$ : this demonstrates that assessments of future impacts on labour productivity should incorporate the seasonality of agricultural labour.

In this article, we estimate the labour productivity effects of climate change for rice harvesting specifically, based on data from global climate models, weather reanalysis, and a database of rice production. Other studies have made estimates of the labour productivity effects of climate change in a more general scope; we examine some of the assumptions used in these studies. We identify the distribution of labour through the year as an important assumption in relation to agricultural production. We also note the importance of mechanization, the potential for adaptation to higher heat conditions, and the difficulty of accounting for these factors. 


\section{Methods}

In this study we analyse data from the Coupled Model Intercomparison Project, Phase $6(\mathrm{CMIP6})^{11}$, comprised of global climate models that have been run in a shared experimental configuration. The model outputs used here are daily mean and maximum temperature, specific humidity, and surface level pressure. All 14 CMIP6 models for which appropriate data were present in the Centre for Environmental Data Analysis (CEDA) $\operatorname{archive}^{1}$ were included. CMIP historical runs and ScenarioMIP ${ }^{12}$ future pathways were processed. ScenarioMIP runs simulate the future climate given assumptions about future emissions (especially of greenhouse gases) and development pathways called Shared Socioeconomic Pathways (SSPs). For each climate model and scenario, only the first ensemble member was processed to ensure climate models were equally weighted. A table of model runs used, with data citations, is included in the supplementary material. The Climatic Research Unit gridded Time Series (CRUTS) 4.03 ${ }^{13,14}$, and the European Centre for MediumRange Weather Forecasts Reanalysis 5 (ERA5) ${ }^{15}$, were used as historical observational datasets.

Daily frequency CMIP6 data were used. Sub-daily data for the variables of interest were available for only a small number of models. Daytime temperature variation was estimated by assuming the temperature is close to the daily mean temperature, daily max temperature, and the mid-point of the two, for 4 hours each, following previous studies ${ }^{6}$. Comparing the result of this calculation using 3-hourly and daily CMIP6 data, we found that this is a reasonable approximation (see Supplementary Material). Daily ERA5 data were used to maintain consistency with the CMIP6 data. CRUTS 4.03 is monthly and is only included as a crosscheck.

Wet-bulb globe temperature (WBGT) is a heat-stress metric defined by ISO 7243 and widely used for assessing hazards due to hot conditions ${ }^{16-18}$. WBGT is intended to combine the factors that affect the human experience of heat: namely air temperature, radiant temperature, humidity, and air velocity ${ }^{17}$. WBGT is designed to be measured directly using specialised equipment; in practice, statistical and empirical formulae for estimating it from standard meteorological variables must be used in the climate context. We assumed

${ }^{1}$ http://archive.ceda.ac.uk/ 
that work occurs in the shade, so that air temperature approximates black-globe temperature (BGT).

Furthermore, cloud cover is one of the most uncertain aspects of global climate models ${ }^{19}$. In the supplementary material, we explore the effect of excluding radiation: although this leads to underestimation of heat stress in some conditions, it makes little difference to long-term trends and is consistent with other related studies ${ }^{6,20,21}$. WBGT was calculated as WBGT $=0.7 *$ WBT $+0.3 * \mathrm{BGT}$, where WBT is the wetbulb temperature. WBT was calculated from air temperature, specific humidity, and pressure using opensource software 'psychrolib'22 which implements formulae from the American Society of Heating, Refrigerating and Air-Conditioning Engineers handbook. Field measured WBT decreases with wind speed at low speed ( $<2 \mathrm{~m} / \mathrm{s}$, a light breeze), but higher wind speeds have a lesser effect ${ }^{23}$. The WBT calculation used is consistent with a light breeze, and variation in wind speed is neglected.

Studies of occupational heat stress under climate change often either assume a threshold in WBGT above which a worker is at risk ${ }^{24}$, or assume that there is a simple relationship between WBGT and worker productivity. Typically, these relationships are assumed to be representative across sectors, and are based on either a regulatory or advisory standard ${ }^{20}$, limited field study or survey data, or an ad hoc fusion of the two ${ }^{6,21,25}$. Regulations attempt to minimise harm, so appear conservative when compared to the actual conditions in which people work. Field data measuring the effect of heat on worker productivity are sparse and cover only a few activities: studies of small numbers of workers are often used to estimate productivity effects on the entire human population.

Sahu, Sett and Kjellstrom (2019) $)^{4}$ observed a $5 \%$ per ${ }^{\circ} \mathrm{C}$ WBGT decrease in the labour capacity of labourers harvesting rice between $23-33^{\circ} \mathrm{C}$ WBGT. Rate of collection was measured in 124 workers in groups of 10-18, and WBGT was measured in-situ, at an individual location in India. We adopt this for our labour impact metric and assume that this is representative of manual rice harvest labour. The impact is assumed to be linear in WBGT, although this assumption must break down at high WBGT $\left(>35^{\circ} \mathrm{C}\right)$. The systematic uncertainty due to these assumptions cannot be assessed without larger scale field observations. The labour 
loss function is $5.14 *$ WBGT -218 , in units of $\%$, clipped at 0 and 100 . This means that $0 \%$ loss occurs at 23 ${ }^{\circ} \mathrm{C}$ and $100 \%$ loss occurs at $42.5^{\circ} \mathrm{C}$.

To facilitate comparison to other studies, results were also calculated using different assumptions about the relationship between WBGT and labour productivity: the heavy labour assumption used in Dunne, Stouffer, and John $(2013)^{20}$, and the heavy labour assumption used in Orlov et al. (2020) ${ }^{26}$. Our calculations are consistent with these other studies. In the supplementary material, equations for each of these and the effect of varying the assumptions are shown.

The RiceAtlas dataset ${ }^{8,9}$ provides detailed data on rice production, broken down into location entities with an average area of $5000 \mathrm{~km}^{2}$. Information such as yield, harvested area, planting and harvesting dates are included, and many entities have multiple yearly harvests. The data are representative of the years 2010-2012. We used this to identify harvest dates. Location entities in RiceAtlas vary greatly in size, and many are much smaller than the grid spacing of the climate models considered. Where a location enclosed multiple climate-model grid-cells, the mean was taken of the enclosed cells; otherwise, the land grid-point closest to the centroid of the location was used. We used data only for countries in Asia; see Table 1.

For each location and harvest season, climate data (ERA5 and CRUTS 4.03, and CMIP6 outputs) were selected using the harvest dates and spatial geometry provided by RiceAtlas, and WBGT calculated. Then, the labour impact metric was calculated from WBGT. Independently for each climate model, and for each location and season, a linear trend was fitted between the 20-year means of the change in the global mean near-surface air temperature (GSAT) and the labour productivity metric. As the labour productivity function was clipped at zero, the fitted function was too. We assumed that $1{ }^{\circ} \mathrm{C}$ of GSAT warming relative to $1850-$ 1900 was representative of the present (2020), and changes in both variables are relative to the present. Data from historical model runs and different SSPs were included together in a single fit, so that a range of GSAT values (up to $4{ }^{\circ} \mathrm{C}$ relative to $1850-1900$ ) were included; but each model, and harvest season and location was fit independently. We defined the gradient of this fit as the "hazard gradient", the purpose of which is to summarise the relationship between changes in GSAT and local changes in labour productivity via 
WBGT, to explore the spatial patterns of change. This effectively collapses variation in time, the climate sensitivity of each model, and emissions scenario into a single dimension.

The multi-model mean of the hazard gradient was calculated for each harvest season and location. The labour impact was also averaged over all regions, weighted by total rice production, to characterise the global situation.

\section{Results}

Figure 2 shows the Asia-wide average of the heat impact on rice harvest labour, calculated from the historical observational and reanalysis datasets, weighted by total rice production in each harvest season and location. There is a statistically significant increase $(p<<0.01)$ over the full observational period (19002018) of CRU-TS, and in both datasets for the common observational period (1980-2018): the heat hazard associated with the rice harvest has already increased.

Figure 3 shows heat impact on Asia-wide rice harvest labour plotted against GSAT warming across various climate models. Changes are relative to the present, assumed to mean $1{ }^{\circ} \mathrm{C}$ of warming over $1850-$ 1900. The rice harvest labour impact is weighted by total rice production. In Figure 3a, each point is a 20 year mean in a single model simulation. Despite the different biases and climate sensitivities of the models, they each show a linear relationship between GSAT and the rice harvest labour impact. All models have a hazard gradient $2.0-2.7 \% /{ }^{\circ} \mathrm{C}, \mathrm{p}<<0.01, \mathrm{R}^{2}>0.98$. The multi-model mean (standard deviation) of the hazard gradient is $2.3(0.2) \% /{ }^{\circ} \mathrm{C}$. A single trend line is shown in figure 3 a for illustration only.

In Figure $3 b$, the Asia-wide labour impact is linearly interpolated to $1.5,2.0$ and $3.0^{\circ} \mathrm{C}$ of warming (relative to 1850-1900) individually for each model, and results are shown as a multi-model boxplot. There is a statistically significant difference (>3 standard deviations) between the $1.0^{\circ} \mathrm{C}$ and $1.5^{\circ} \mathrm{C}$ of warming with multi-model mean (standard deviation) $1.0(0.3) \%$; between 1.5 and $2.0^{\circ} \mathrm{C}$ of $1.3(0.2) \%$; as well as between 2.0 and $3.0^{\circ} \mathrm{C}$ of $2.6(0.4) \% . \mathrm{KS}$ test and T test $\mathrm{p}$-values on the multi-model distributions are small $(<<0.001)$ for each case. 
As the Asia-wide analysis is weighted according to total rice production in each location and season, the Asia-wide results should be interpreted carefully: the average is more sensitive to locations with more intensive cropping. However, the breakdown by location shows that the trends are general, and not skewed by a single area with high cropping intensity. The correlation coefficient between models and within each harvest season and location is 0.95 , suggesting that there is generally high agreement between the models.

Figure 4 shows the distribution of the multi-model mean hazard-gradient across harvest seasons and locations. In the blue histogram, the entire year is given equal weight in the heat stress calculation. Conversely, in the orange histogram, only the rice harvest season is considered in the heat stress calculation. Both histograms are weighted by rice production. Considering the time of year at which the rice harvest occurs, as opposed to the whole of the year, leads to some rice harvests having higher hazard-gradient, but other harvests not having a significant hazard-gradient. If the harvest season and locations with nonsignificant hazard-gradients are excluded, then the mean hazard-gradient is increased. The interquartile range of the distribution in orange is more than double that in blue. The two assumptions lead to completely different distributions of hazard gradient, showing the importance of including the seasonality of labour in projections of the effect of heat-stress on agricultural labour productivity.

The $50 \%$ of rice production with the highest hazard gradients between GSAT change and labour impact (hazard gradient $>3.05 \% /{ }^{\circ} \mathrm{C}$ ) is identified as being exposed to a high hazard-gradient; the proportion of exposed production in each location is mapped in Figure 5 and listed by country in Table 1 . We do this to identify regional differences in the estimated labour impact; we are not suggesting this is a limit to adaptation. Areas identified by this method include most of Southeast Asia, and coastal South Asia. Harvests in northern India (e.g., in Punjab) are not strongly affected.

Figure 6 shows the hazard gradient for each harvest season and location, plotted against latitude in $6 a$ and against the peak month of the harvest season in $6 \mathrm{c}$. Figure $6 \mathrm{~b}$ shows the hazard gradient against latitude assuming the full year is equally weighted. Two interacting effects explain most of the spatial variation in the results. Firstly, locations close to the equator have higher temperatures. Secondly, for locations that are 
further from the equator there is greater seasonal variation in temperature, so the time of year at which the harvest occurs is important. Figure $6 \mathrm{~b}$ shows that if the time of year of the harvest is not considered, then the hazard gradient is mostly determined by latitude. As Figure $6 c$ shows, all large harvests that are not exposed to high hazard-gradients peak between September and December inclusive. Close to the equator, for example in Indonesia, hazard gradient is not very seasonally dependent as there is little seasonal variation in temperature. By comparison, in China and India the time of year of the harvest season has a much stronger effect on the hazard gradient.

\section{Discussion}

Global mean surface temperature (GMST) has increased by $0.9-1.2^{\circ} \mathrm{C}$ relative to $1850-1900$ as of $2017^{27}$, and if anthropogenic warming continues to follow recent trends, is projected to reach $1.5 \mathrm{C}$ between 2030 and 2052; the estimated rate of warming is $0.2^{\circ} \mathrm{C}$ per decade ${ }^{28}$. In accordance with the Paris Agreement under the United Nations Framework Convention on Climate Change ${ }^{29}$, most countries have committed to limit GMST warming by 2100 to $2{ }^{\circ} \mathrm{C}$, and to make efforts to limit warming to $1.5^{\circ} \mathrm{C}$. However, at the time of writing, pledges of emissions reductions are not sufficient to meet this goal ${ }^{30}$.

We identify in Figure 2 that there is a statistically significant increase in the estimated heat impact in the historical observational dataset. However, we do not know of any comparable data that attempts to directly measure the heat strain that farm workers are under on a global scale, so the full effects of this are unclear.

Overall, the long-term averages in the estimated labour impact are highly correlated with GSAT change (Figure 3). This is not surprising as the labour impact metric is linear in WBGT above a threshold, and GSAT change (i.e., global warming) dominates large-scale, long-term trends in WBGT. This relationship holds at the Asia-wide level, but also individually for most location and seasons. Therefore, we suggest that when there is a strong relationship between GSAT and the metric being considered, it may aid interpretation to plot against GSAT across all scenarios, rather than against year for each scenario. 
Labour inputs to rice production are seasonal, with more labour occurring around planting and harvesting ${ }^{31-33}$. This labour cannot be delayed or displaced to other times of year, and the timeliness of these activities affects yield and quality. Averaging across the full year assumes that labour for any given activity can be exchanged with labour at a different time of year, which is clearly not the case for planting and harvesting. In this study, we have shown the importance of considering the seasonality of agricultural labour when estimating the effect of heat-stress on labour productivity. We have focussed only on harvesting, and only on rice; however, each crop and each labour-intensive part of production will have its own the seasonality that should be incorporated into estimates. Other studies into the effect of climate change on labour productivity, even those focussed on agricultural labour, do not take this into account $\mathrm{t}^{6,21,26,34}$.

In some cases, especially wheat in Punjab, rice is multi-cropped with another crop not covered in this study, for which harvest labour may be more exposed. Studies have suggested that changes to planting and harvesting dates ${ }^{35}$, and crop choice ${ }^{36}$, could be used to adapt to climate change and mitigate negative effects on yields. Changes to planting and harvesting dates, to maximise yield as temperature and precipitation patterns change, is a complex topic, and outside the scope of this study. Given that the world has already experienced $1{ }^{\circ} \mathrm{C}$ of warming, such adaptations may already be occurring. Changes to planting and harvesting dates could lead to workers being exposed to heat stress in locations where they currently are not, and this should be considered when studying adaptive measures.

Vulnerability may be higher in locations with less farm mechanization, but we note that high-quality international data on farm mechanization are lacking: for example, World Bank statistics on agricultural machinery are not collected on a regular time basis, and only cover certain machinery. Assuming gross domestic product as a proxy for mechanization could be misleading, as variation between countries will be dominated by the variation between high income countries and LIC, rather than the variation between and within LIC and LMIC where agricultural workers are likely to be most at risk from heat stress.

Farm mechanisation in Asia over the past 50 years has been driven by small internal combustion engines, which have already alleviated much of the human drudgery of farming, reduced the use of draft 
animals, and increased yields ${ }^{37,38}$. However, more fatal injuries occur when using powered machinery ${ }^{38}$, and the use of internal combustion engines contributes to greenhouse gas emissions.

Despite the lack of comparable international data, some qualitative comparisons can be made between and within countries. Mechanization of power intensive operations such as pumping, tilling, and threshing often coexist with manual seeding, weeding, crop care, and harvesting. Mechanization of power intensive operations is economically advantageous, even when wages are low, if demand for crops is sufficiently elastic to favour intensification. The remaining manual operations tend to be mechanized when agricultural wages rise due to economic development ${ }^{39}$. Power intensive operations are widely mechanized across Asia ${ }^{37,39,40}$, and manual operations may gradually disappear because of economic development. Small holding size is not necessarily a barrier to mechanization, due to machinery hiring services ${ }^{40}$.

According to the models of heat stress widely used in evaluations of the effect of climate change on labour productivity, labour productivity is still affected by heat stress even when labour is made less physically intensive by mechanization ${ }^{6,20,26}$. Other crops not discussed in this study are less suitable for mechanical harvesting, so may be more vulnerable. Vulnerability may be higher in parts of sub-Saharan Africa where there has been less uptake of agricultural machinery ${ }^{39,40}$.

A survey by Bordey et al. $(2016)^{32}$ suggested that production is much more labour intensive in the Philippines, Indonesia, and India, (>65 worker-days per hectare) compared in China, Thailand, and Vietnam (10-20 worker-days per hectare). Furthermore, almost all farmers surveyed in India, China, Thailand, and Vietnam made use of combine harvesters. However, these surveys were not designed to be representative of all farms in those countries, and cover a limited number of locations close to research centres. According to the same survey, the Philippines and Indonesia especially rely on manual harvesting. There are substantial variations within countries that may be important and difficult to account for: for example, the rice bowl regions of Thailand and the Philippines have high levels of mechanization for land preparation, but areas within those countries that are less favourable for rice production continue to use animal draft power ${ }^{39}$. 
Mechanization in India varies between states. Four-wheel tractor (4WT) density is highest in Haryana $^{2}$ and Punjab (>100 4WT per 1000 ha), and lowest in Kerala and West Bengal $(<10$ 4WT per 1000 ha $)^{40}$ (2012 estimates). Assuming mechanization is homogeneous across a large country such as India will lead to underestimating the vulnerability of some locations. In Bangladesh, land preparation is mechanized, but harvesting is not ${ }^{40,41}$, with on average 5 4WTs per 1000 ha and 0.01 combine harvesters per 1000 ha (2014 estimates). Adoption of machinery is increasing in India, Bangladesh, and Sri Lanka, when 4WT, 2wheel tractors, and combine harvesters are considered together ${ }^{40}$. Due to labour-intensive manual harvesting, and high hazard-gradient (see Table 1), we highlight rice harvest labour as being vulnerable and exposed to increasing human heat stress due to global warming in Indonesia, the Philippines, and Bangladesh, as well as the Indian states of Kerala, and West Bengal. Other locations are exposed to the hazard, and may be vulnerable, but data concerning mechanization of harvests is lacking.

Workers may be able to reduce heat exposure by starting work early in the morning when it is cooler, but this could mean working in the dark. Reducing work hours could also reduce heat exposure but could exacerbate labour shortage and reduce worker income. We note that the workers observed by Sahu, Sett and Kjellstrom (2019) began their work near dawn and were still exposed to hazardous heat in their first hour of work ${ }^{4}$.

The accuracy, coverage, and granularity of the rice crop data limits our study. However, by focussing on long-term trends with high levels of multi-model agreement, we avoid the issue of climate model bias. The assumed linear effect of WBGT on labour productivity comes from a single field study and cannot be accurate as WBGT approaches known human physiological limits, but the general conclusions are unchanged by substituting other labour-impact functions from the literature. Due to the resolution of climate models, results will be less reliable for locations with steep gradients in altitude, for example Nepal.

\footnotetext{
${ }^{2}$ Subnational locations mentioned in the article have Hierarchical administrative subdivision codes (HASC) listed in the supplementary material. A full list of HASC with country, region, and sub-region names is included in the data supplement.
} 
El Nino is an important driver of annual temperature variation in the region, and negatively affects crops through rainfall patterns (see e.g. ${ }^{42}$ ). Higher global temperatures could change El Nino patterns, but this is beyond the scope of this study. We have focussed on long term trends on the scale of 20 years rather than extreme events, but WBT extremes are also closely correlated with large-scale mean temperatures within the tropics ${ }^{43}$.

\section{Conclusion}

The rising impact of heat on rice harvest labour will be unevenly distributed, falling on poor rural workers who will be least able to adapt, and therefore contributing to widening economic inequality. Given agriculture employs hundreds of millions of people, a few-percent shift in labour capacity is equivalent to the labour of millions of people. Labour productivity decreases due to climate change will compound other environmental impacts on rice production, including declining yields as direct result of increasing temperature ${ }^{44}$, water stress, and sea level rise ${ }^{28}$; contributing to the unequal loss and damage created by climate change.

We see a strong relationship between heat hazard and GSAT change in the rice harvest seasons and locations of Asia, with a high level of agreement between climate models. Historical observational data shows already shows a statistically significant increase in our labour impact metric. Understanding disparities in the heat-stress exposure of workers and industries around the world will be important for climate adaptation strategy, as well as estimation of loss and damage. Overall, the exposure of such a large proportion of rice agriculture, and the workers engaged therein, provides an argument for strong mitigation of climate change.

We have chosen to focus on rice harvesting, but all of issues discussed apply to other crops: key activities have different amenability to mechanization and different work intensities, and labour is not evenly spread throughout the year. Assuming that labour is equally distributed through the year leads to underestimation of the effect of climate change on the heat stress of agricultural workers in many places. Accurate accounting for the balance of mechanization and manual labour remains difficult. 
Table 1: Rice production exposed to hazard gradient above the $50^{\text {th }}$ percentile by country, and Asia total. Countries with less than 1 million tonnes of annual rice production are not included. Rice production from RiceAtlas ${ }^{8}$. We define hazard gradient as the gradient between GSAT and local labour impact.

\begin{tabular}{|c|c|c|c|}
\hline COUNTRY & $\begin{array}{l}\text { Production above } \\
\text { 50th percentile of } \\
\text { hazard gradient (\%) }\end{array}$ & $\begin{array}{l}\text { Total } \\
\text { production } \\
\text { (million } \\
\text { tonnes) }\end{array}$ & $\begin{array}{l}\text { Production above } \\
\text { 50th percentile of } \\
\text { hazard gradient } \\
\text { (million tonnes) }\end{array}$ \\
\hline Asia & 50 & 646 & 323 \\
\hline Indonesia & 100 & 67 & 67 \\
\hline India & 36 & 151 & 55 \\
\hline China & 27 & 200 & 55 \\
\hline Vietnam & 83 & 42 & 35 \\
\hline Thailand & 77 & 36 & 28 \\
\hline Bangladesh & 61 & 45 & 27 \\
\hline Myanmar & 71 & 32 & 23 \\
\hline Philippines & 94 & 17 & 16 \\
\hline Cambodia & 75 & 9 & 7 \\
\hline Sri Lanka & 100 & 4 & 4 \\
\hline Malaysia & 100 & 3 & 3 \\
\hline Japan & 29 & 8 & 2 \\
\hline Taiwan & 70 & 2 & 1 \\
\hline Laos & 25 & 3 & 1 \\
\hline South Korea & 0 & 6 & 0 \\
\hline Nepal & 0 & 5 & 0 \\
\hline North Korea & 0 & 2 & 0 \\
\hline Pakistan & 0 & 9 & 0 \\
\hline Iran & 0 & 3 & 0 \\
\hline
\end{tabular}



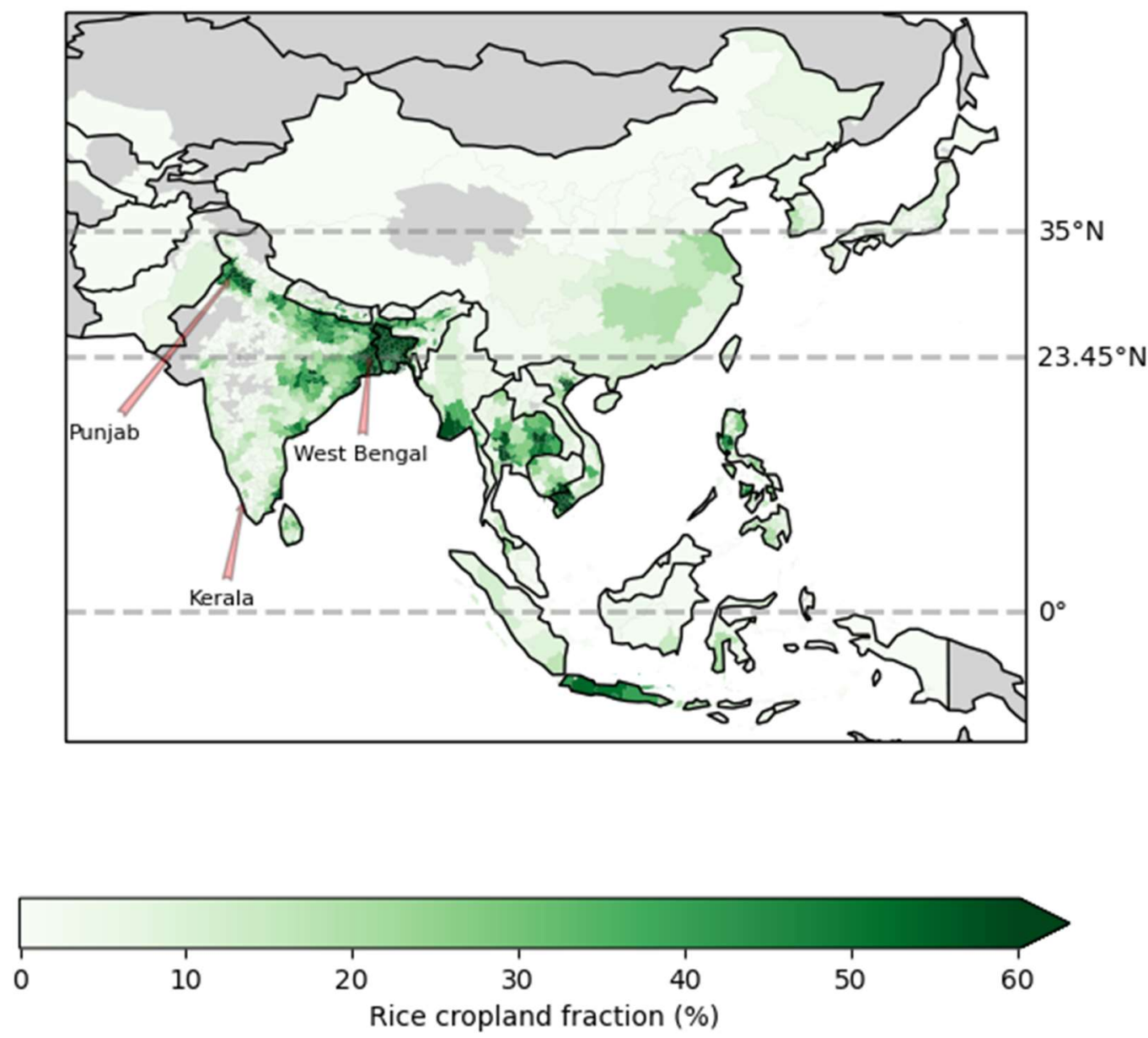

Figure 1: Geographical distribution of rice production across Asia (green shading). Sub-national locations mentioned in the article are labelled. Data sourced from RiceAtlas ${ }^{8}$. 


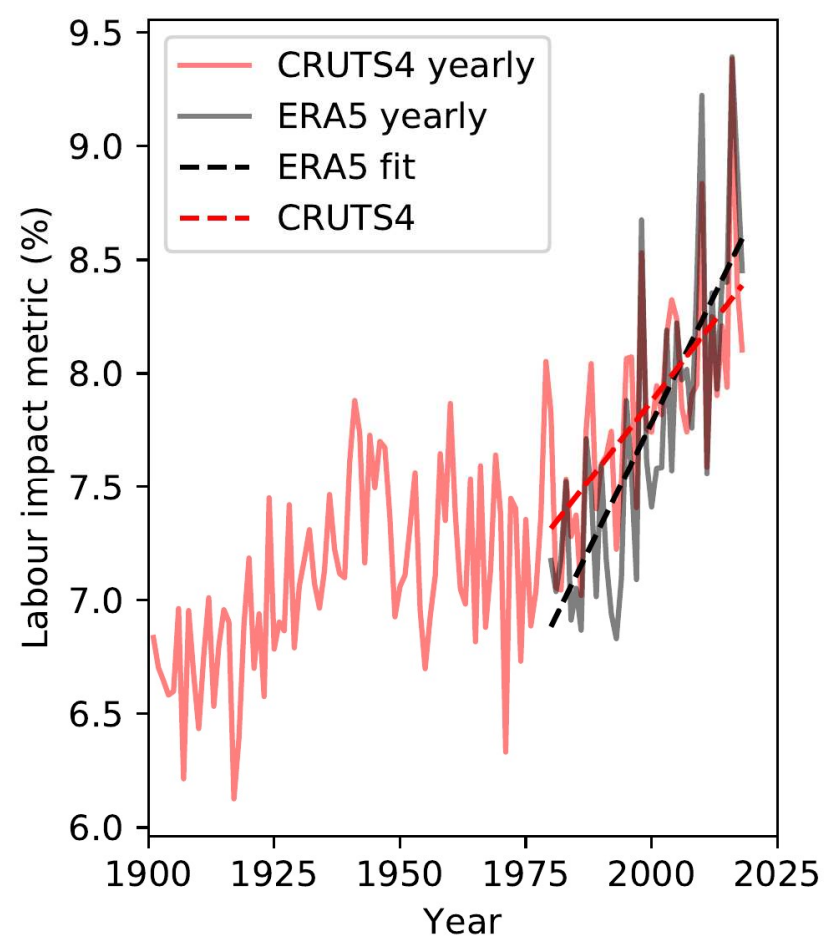

Figure 2: Annual Asia-wide mean labour impact, weighted by total rice production, calculated from CRU-TS 4.03 (red lines) and ERA5 (black line), with trend lines (dashed) shown for the period 1980-2018 

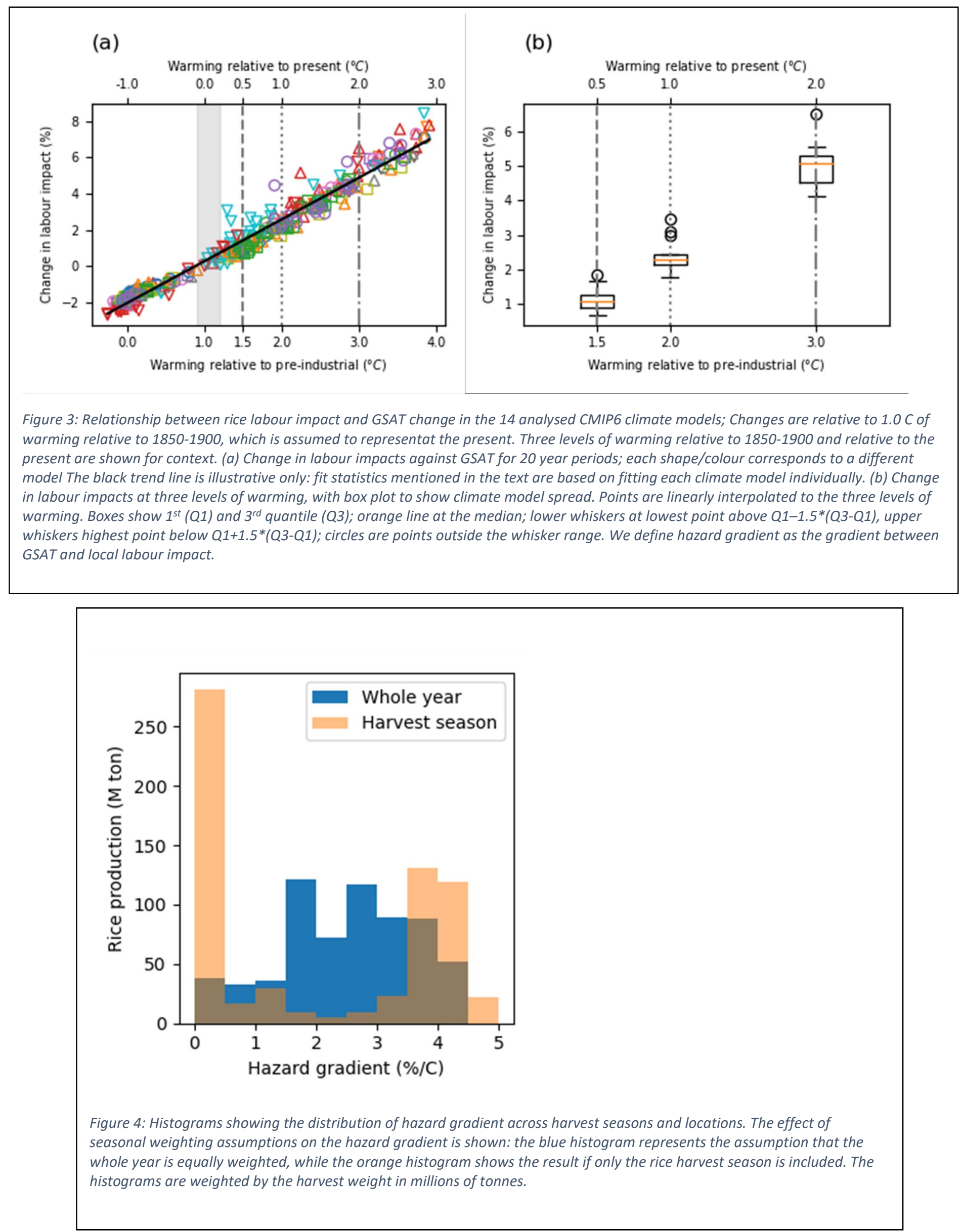

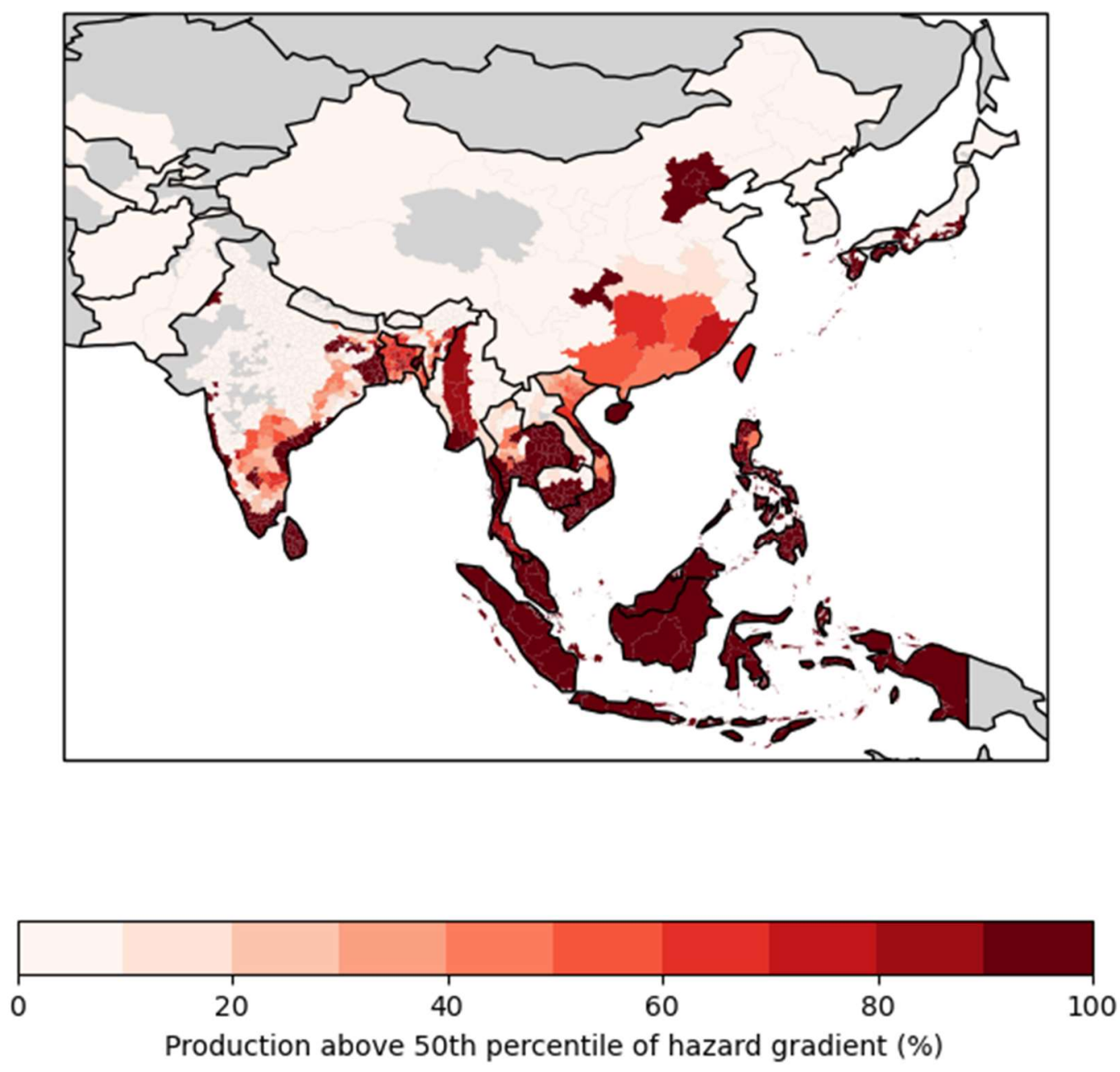


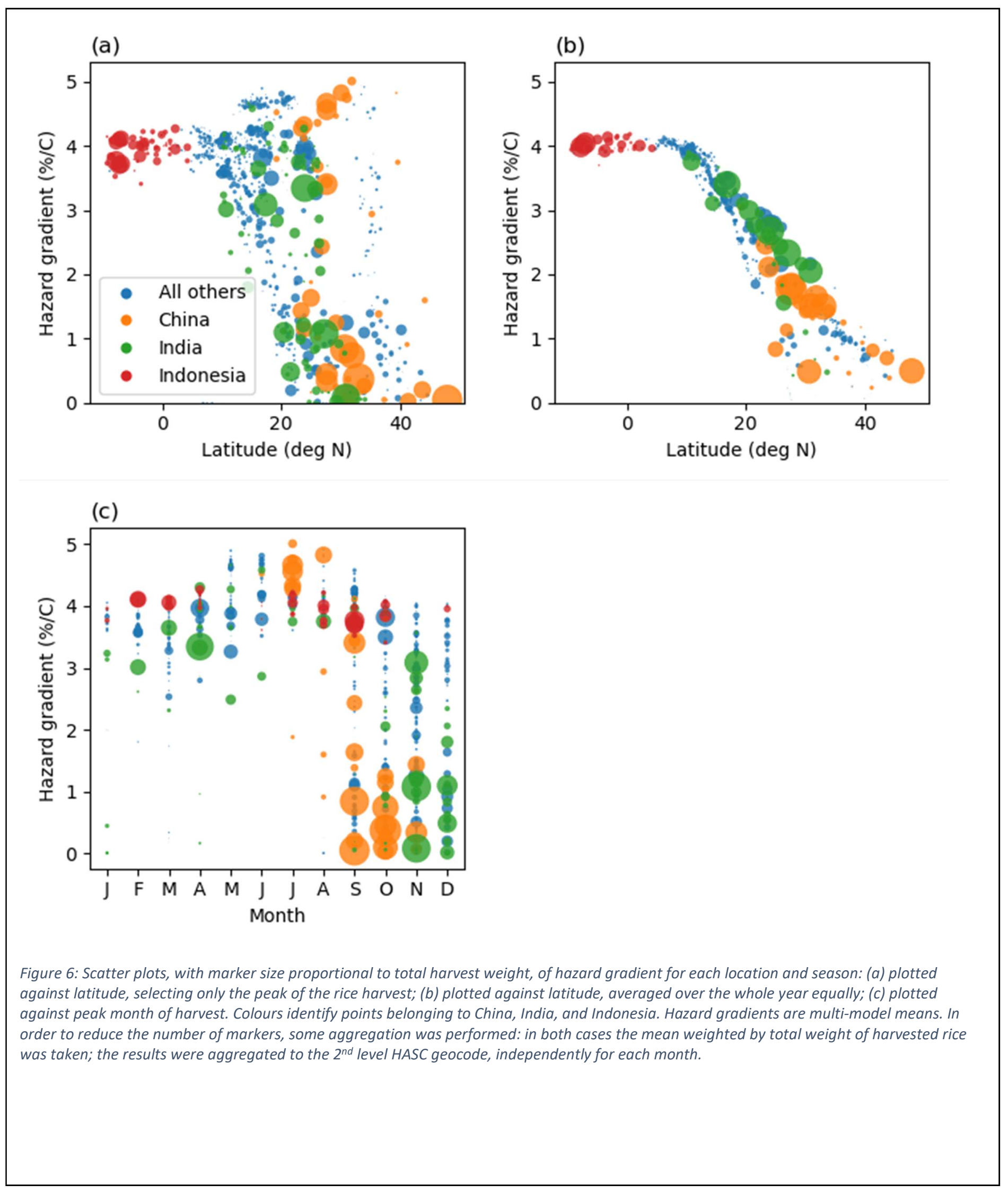




\section{Acknowledgements}

All authors are funded by the NERC EMERGENCE project: CS, JSH and ES by NE/S004726/1, RAB by $\mathrm{NE} / \mathrm{S} 004645 / 1$, and DM by NE/S005242/1. The work of RAB also forms part of the BEIS/Defra Met Office Hadley Centre Climate Programme (GA01101). This project made use of the JASMIN computer service (jasmin.ac.uk), and CEDA archive (ceda.ac.uk). Thanks to the developers of the following software packages: Geopandas, Xarray, Cartopy, Psychrolib.

\section{Data and code availability statement}

The datasets generated during the study are freely available from Zenodo https://doi.org/10.5281/zenodo.4737471. A code demonstration can be found at https://github.com/C-HSimpson/HarvestOccupationalHeat (a Zenodo archived version with a DOI will be created before publication).

\section{Author contribution statement}

CS performed the analysis and mostly wrote the paper. JSH, DM, RAB, and ES helped develop the ideas for the analysis, and advised on the wording and emphasis of the paper.

\section{Competing interest statement}

The authors declare no competing interests. 


\section{References}

1. International Labour Organization. Employment by sex and economic activity -- ILO modelled estimates. https://ilostat.ilo.org/ (2019).

2. Moyce, S. et al. Heat strain, volume depletion and kidney function in California agricultural workers. Occup. Environ. Med. 74, 402-409 (2017).

3. Crowe, J. et al. Heat exposure in sugarcane harvesters in Costa Rica. Am. J. Ind. Med. 56, 1157-1164 (2013).

4. Sahu, S., Sett, M. \& Kjellstrom, T. Heat Exposure, Cardiovascular Stress and Work Productivity in Rice Harvesters in India: Implications for a Climate Change Future. Ind. Health 51, 424-431 (2013).

5. Zhao, Y., Ducharne, A., Sultan, B., Braconnot, P. \& Vautard, R. Estimating heat stress from climatebased indicators: Present-day biases and future spreads in the CMIP5 global climate model ensemble. Environ. Res. Lett. 10, 84013 (2015).

6. Kjellstrom, T., Freyberg, C., Lemke, B., Otto, M. \& Briggs, D. Estimating population heat exposure and impacts on working people in conjunction with climate change. Int. J. Biometeorol. 62, 291-306 (2018).

7. Coffel, E. D., Horton, R. M. \& De Sherbinin, A. Temperature and humidity based projections of a rapid rise in global heat stress exposure during the 21st century. Environmental Research Letters vol. 13 (2018).

8. Laborte, A. G. et al. RiceAtlas, a spatial database of global rice calendars and production. Sci. Data 4, 1-10 (2017).

9. Laborte, A. G. et al. RiceAtlas, a spatial database of global rice calendars and production (dataset). (2017) doi:10.7910/DVN/JE6R2R.

10. Food and Agriculture Organization of the United Nations (FAO). Value of Agricultural Production. License: CC BY-NC-SA 3.0 IGO http://www.fao.org/faostat/en/\#data/QV/ (2019).

11. Eyring, V. et al. Overview of the Coupled Model Intercomparison Project Phase 6 (CMIP6) experimental design and organization. Geosci. Model Dev 9, 1937-1958 (2016).

12. O'Neill, B. C. et al. The Scenario Model Intercomparison Project (ScenarioMIP) for CMIP6. Geosci. Model Dev. 9, 3461-3482 (2016).

13. Harris, I., Osborn, T. J., Jones, P. \& Lister, D. Version 4 of the CRU TS monthly high-resolution gridded multivariate climate dataset. Sci. Data 7, 1-18 (2020).

14. University of East Anglia Climatic Research Unit, Harris, I. C. \& Jones, P. D. CRU TS4.03: Climatic Research Unit (CRU) Time-Series (TS) version 4.03 of high-resolution gridded data of month-by-month variation in climate (Jan. 1901- Dec. 2018). (2020) doi:10.5285/10d3e3640f004c578403419aac167d82.

15. Hersbach, H. et al. The ERA5 global reanalysis. Q. J. R. Meteorol. Soc. 146, 1999-2049 (2020).

16. Epstein, Y. \& Moran, D. S. Thermal Comfort and the Heat Stress Indices. Ind. Health 44, 388-398 (2006).

17. Parsons, K. Heat stress standard ISO 7243 and its global application. Industrial Health vol. 44 368-379 (2006).

18. Parsons, K. Occupational Health Impacts of Climate Change: Current and Future ISO Standards for the Assessment of Heat Stress. Ind. Health 51, 86-100 (2013). 
19. Vial, J., Dufresne, J.-L. \& Bony, S. On the interpretation of inter-model spread in CMIP5 climate sensitivity estimates. Clim. Dyn. 41, 3339-3362 (2013).

20. Dunne, J. P., Stouffer, R. J. \& John, J. G. Reductions in labour capacity from heat stress under climate warming. Nat. Clim. Chang. 3, 563-566 (2013).

21. Watts, N. et al. The 2020 report of The Lancet Countdown on health and climate change: responding to converging crises. The Lancet vol. 397 129-170 (2021).

22. Meyer, D. \& Thevenard, D. PsychroLib: a library of psychrometric functions to calculate thermodynamic properties of air. J. Open Source Softw. 4, 1137 (2019).

23. Lemke, B. \& Kjellstrom, T. Calculating Workplace WBGT from Meteorological Data: A Tool for Climate Change Assessment. Ind. Health 50, 267-278 (2012).

24. Andrews, O., Le Quéré, C., Kjellstrom, T., Lemke, B. \& Haines, A. Implications for workability and survivability in populations exposed to extreme heat under climate change: a modelling study. Lancet Planet. Heal. 2, e540-e547 (2018).

25. Gosling, S. N., Zaherpour, J. \& Ibarreta, D. PESETA III: Climate change impacts on labour productivity. (Publications Office of the European Union, 2018). doi:10.2760/07911.

26. Orlov, A., Sillmann, J., Aunan, K., Kjellstrom, T. \& Aaheim, A. Economic costs of heat-induced reductions in worker productivity due to global warming. Glob. Environ. Chang. 63, (2020).

27. Haustein, K. et al. A real-time Global Warming Index. Sci. Rep. 7, 1-6 (2017).

28. Masson-Delmotte, V. et al. Global warming of $1.5^{\circ} \mathrm{C}$. (International Panel on Climate Change, 2019).

29. Conference of the Parties. Adoption of the Paris Agreement. U.N. Doc. FCCC/CP/2015/L.9/Rev/1 (2015).

30. Raftery, A. E., Zimmer, A., Frierson, D. M. W., Startz, R. \& Liu, P. Less than $2{ }^{\circ} \mathrm{C}$ warming by 2100 unlikely. Nat. Clim. Chang. 7, 637-641 (2017).

31. Singh, G. \& Chancellor, W. Energy Inputs and Agricultural Production under Various Regimes of Mechanization in Northern India. (2016) doi:10.13031/2013.38695.

32. Bordey, F. H., Moya, P. F., Beltran, J. C. \& Dawe, D. C. Competitiveness of Philippine Rice in Asia. International Rice Research Institute (Philippine Rice Research Institute, 2016).

33. Quilty, J. R. et al. Energy efficiency of rice production in farmers' fields and intensively cropped research fields in the Philippines. F. Crop. Res. 168, 8-18 (2014).

34. De Lima, C. Z. et al. Heat stress on agricultural workers exacerbates crop impacts of climate change. Environ. Res. Lett 16, 44020 (2021).

35. Jalota, S. K. et al. Mitigating future climate change effects by shifting planting dates of crops in ricewheat cropping system. Reg. Environ. Chang. (2012) doi:10.1007/s10113-012-0300-y.

36. Kurukulasuriya, P. \& Mendelsohn, R. Crop switching as a strategy for adapting to climate change. African Journal of Agricultural and Resource Economics vol. 2 http://ageconsearch.umn.edu/record/56970 (2008).

37. Justice, S. \& Biggs, S. The spread of smaller engines and markets in machinery services in rural areas of South Asia. J. Rural Stud. 73, 10-20 (2020).

38. Nag, P. K. \& Nag, A. Drudgery, Accidents and Injuries in Indian Agriculture. Industrial Health vol. 42 149-162 (2004). 
39. Pingali, P. Agricultural Mechanization: Adoption Patterns and Economic Impact. in Handbook of Agricultural Economics vol. 3 2779-2805 (Elsevier, 2007).

40. Diao, X., Takeshima, H. \& Zhang, X. An evolving paradigm of agricultural mechanization development: How much can Africa learn from Asia? (International Food Policy Research Institute (IFPRI), 2020). doi:10.2499/9780896293809.

41. Islam, A. K. M. S. Status of rice farming mechanization in Bangladesh. J. Biosci. Agric. Res. 17, 13861395 (2018).

42. Selvaraju, R. Impact of El Niño-southern oscillation on Indian foodgrain production. Int. J. Climatol. 23, 187-206 (2003).

43. Zhang, Y., Held, I. \& Fueglistaler, S. Projections of tropical heat stress constrained by atmospheric dynamics. Nat. Geosci. 14, 133-137 (2021).

44. Welch, J. R. et al. Rice yields in tropical/subtropical Asia exhibit large but opposing sensitivities to minimum and maximum temperatures. Natl. Acad Sci. 107, 14562-14567 (2010). 


\section{Supplementary Material}

\section{Evaluation of assumptions}

Key assumptions in this work are: (1) the parameterisation of the daily variation, (2) neglect of radiation, and (3) the labour impact metrics. In order to demonstrate the robustness of our results,

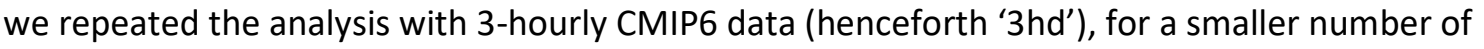
models and only including the ssp585 scenario. The overall conclusions of the analysis (that the metric is strongly correlated with global mean surface temperatures, and that it is important to incorporate the seasonal variation of labour into assessments) are robust against these changes of assumption.

The models used with 3hd were BCC-CSM2-MR, CMCC-CM2-SR5, MIROC6, MPI-ESM1-2-HR, and TaiESM1. This is not the same set of models as the main analysis. Availability of data via the CEDA archive fully determined the selection. To simplify the 3 hd calculation, the labour impact metric was aggregated to a monthly time basis, and harvest seasons selected by peak month, rather than using the day of the year.

\section{Evaluation of daily variation assumption}

In the main analysis of this study we assumed that the temperature is close to the daily mean temperature, daily max temperature, and the mid-point of the two for 4 hours each during the daytime (henceforth ' 444 assumption'). This is following the method used in ${ }^{1}$, and is supposed to be representative of daytime rather than the full diurnal cycle. Daily data were originally used because at the time that the analysis was performed (August 2020), the CEDA archive contained sub-daily data for the variables of interest for only a small number of CMIP6 models.

We compared daily mean labour impact calculated from 3 hd to those calculated from the 444 assumption. We did not make any assumption about which of the 3 hd time steps represented the daytime, and simply took the daily mean. This means that the 3 hd includes nighttime temperatures, whereas 444 does not. Labour impact gradients were also slightly different between 444 and 3 hd, but qualitatively, the conclusions remain the same.

Figure 6a should be compared with Supplementary Figure 1 (SF1), and Figure 6c with SF 5 . There are some visible differences. When 3 hd is used, there is a larger difference in the hazard gradient between the warmer and cooler months. This could be because nighttime temperatures are more likely to be below the threshold of the labour-impact function.

\section{Evaluation of radiation assumption}

In order to examine the assumption about radiation, we used surface down-welling shortwave radiation (CMIP6 variable 'rsds'), to calculate the black-globe temperature following Gaspar and Quintela ${ }^{2}$. To simplify the calculation, we assumed that the effective temperature of the sky is the equal to the surface air temperature, and neglected up-going radiation. We used 3 hd as daily average data would not capture important sub-daily variation in rsds. We found that radiation tends slightly to increase the daily average of the labour impact metric, but that it does not have a noticeable effect on the hazard gradient. This is because long-term trend in air temperature dominates. We note that surface radiation is one of the most uncertain aspects of global climate models. Radiation is important for human heat stress, but the long-term, large-scale change in average WBGT is dominated by air temperature. SF 1 should be compared to SF 2, and SF 5 to SF 6 : they are almost identical. 


\section{Labour-impact metrics}

To examine the difference made by the assumed labour-impact metric, we reproduced the plots with different labour impact metrics. The different metrics are plotted in SF 9. It was convenient to do this using 3 hd.

The impact-metric used by Dunne, Stouffer and John (2013). ${ }^{3}$ is based on regulatory standards for occupational health. The results using this metric are plotted in SF 3 (compare with SF 1) and SF 7 (compare with SF 5); they are visually very similar to the results using the metric from Sahu, Sett, and Kjellstrom (2013). ${ }^{4}$ but with higher numbers. This is because (1) the two functions have a lower threshold at a similar value, (2) the upper threshold is rarely reached for both metrics, and (3) both functions are either linear or close to being linear; but the average gradient of the Dunne, Stouffer and John (2013) metric is higher.

The other labour-impact metric we evaluated was the HOTHAPS high-intensity function. This is used by Orlov et al. $(2020)^{5}$ to represent labour in the crop sector. Comparing SF 4 to SF 1 , and SF 8 to SF 5 , we see that this produces a very noticeable difference. Because of the S-curve form of this labourimpact function, different parts of the WBGT distribution are emphasised. The Sahu, Sett, and Kjellstrom (2013). function gives equal weight to all WBGT > 23 C, whereas the HOTHAPS highintensity function emphasises WBGT close to $31 \mathrm{C}$. This makes consideration of seasonal variation even more important.

The Asia-wide trend against GSAT of both of these rice-weighted metrics has $R^{2}>0.96$ and $p<<0.01$ for every global climate model considered.

Basic results are compatible with those of other studies. Orlov et al. (2020) projected a decrease in work productivity of approximately $18 \%$ and $17 \%$ for South Asia and Southeast Asia respectively, in the crop sector by 2100 under the CMIP5 high-emission scenario. We were able to reproduce similar results by using the labour impact relationship they used, and weighting by population density ${ }^{6}$ : multi-model mean (standard deviation) 14(5)\% and 17(8)\% change between the decade starting 2015 and the decade starting 2090 in SSP585 (a CMIP6 high emissions scenario) for South Asia and Southeast Asia respectively. Using the relationship in Dunne, Stouffer and John (2013), these numbers are $22(5) \%$ and $29(8) \%$.

Table of subnational locations mentioned in text

\begin{tabular}{|l|l|}
\hline Location name & $\begin{array}{l}\text { Hierarchical administrative subdivision codes } \\
\text { (HASC) }\end{array}$ \\
\hline Punjab & IN.PB \\
\hline Haryana & IN.HR \\
\hline Kerala & IN.KL \\
\hline West Bengal & IN.WB \\
\hline
\end{tabular}

The full list of locations used in the analysis can be found in the data supplement.

\section{References}

1. Kjellstrom, T., Freyberg, C., Lemke, B., Otto, M. \& Briggs, D. Estimating population heat exposure and impacts on working people in conjunction with climate change. Int. J. Biometeorol. 62, 291-306 (2018).

2. Gaspar, A. R. \& Quintela, D. A. Physical modelling of globe and natural wet bulb temperatures to predict WBGT heat stress index in outdoor environments. Int. J. Biometeorol. 53, 221-230 (2009).

3. Dunne, J. P., Stouffer, R. J. \& John, J. G. Reductions in labour capacity from heat stress under climate warming. Nat. Clim. Chang. 3, 563-566 (2013). 
4. Sahu, S., Sett, M. \& Kjellstrom, T. Heat Exposure, Cardiovascular Stress and Work Productivity in Rice Harvesters in India: Implications for a Climate Change Future. Ind. Health 51, 424-431 (2013).

5. Orlov, A., Sillmann, J., Aunan, K., Kjellstrom, T. \& Aaheim, A. Economic costs of heat-induced reductions in worker productivity due to global warming. Glob. Environ. Chang. 63, (2020).

6. Center for International Earth Science Information Network Columbia University. Gridded Population of the World, Version 4. doi:10.7927/H4F47M65. 


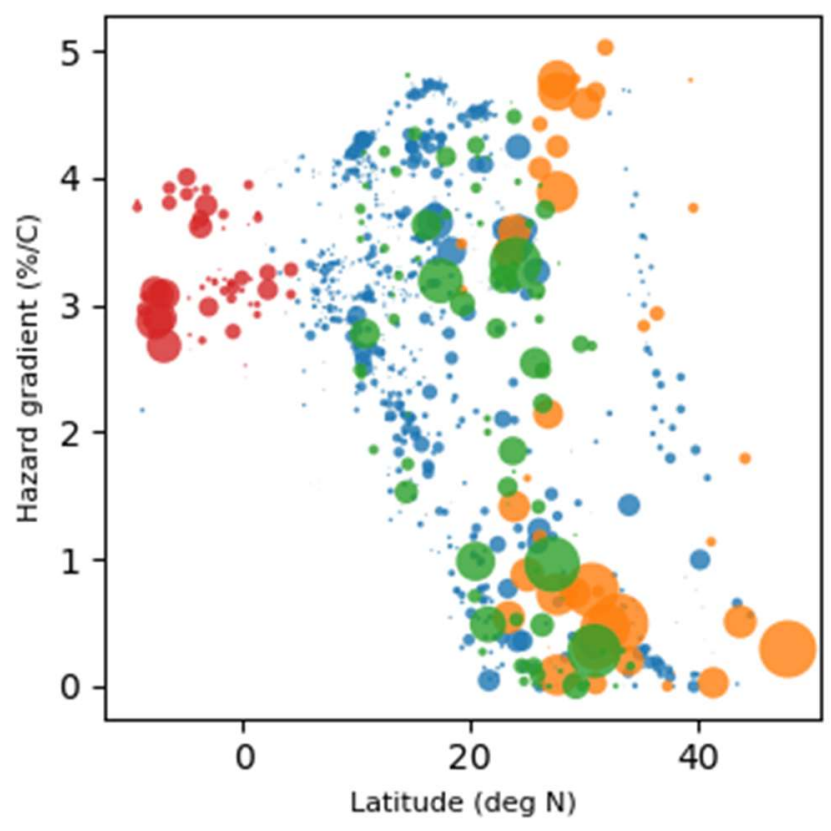

Supplementary Figure 1: As Figure 6a, but calculated from 3-hourly CMIP6 data.

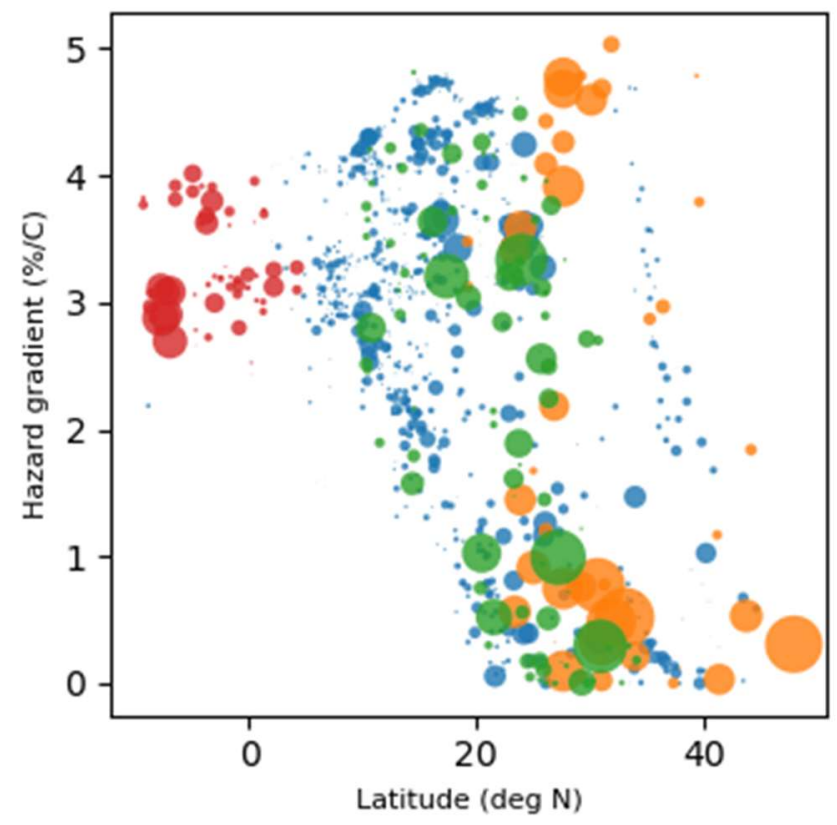

Supplementary Figure 2: Same as Supplementary Figure 1, but including radiation. 


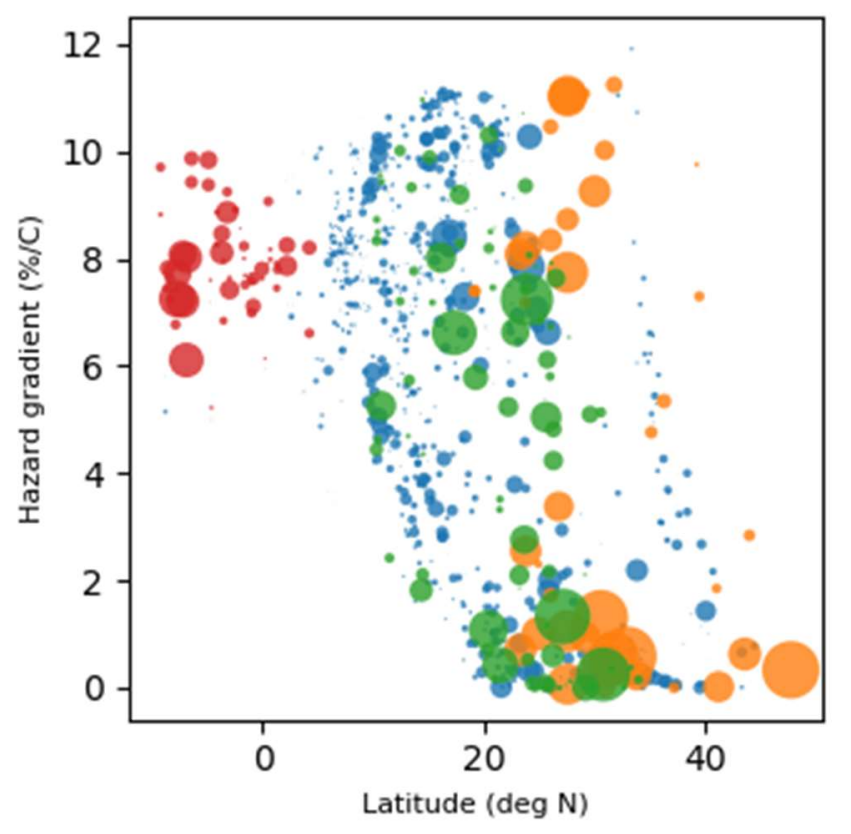

Supplementary Figure 3: Same as Supplementary Figure 1, but using the labour impact metric from Dunne, Stouffer and John (2013).

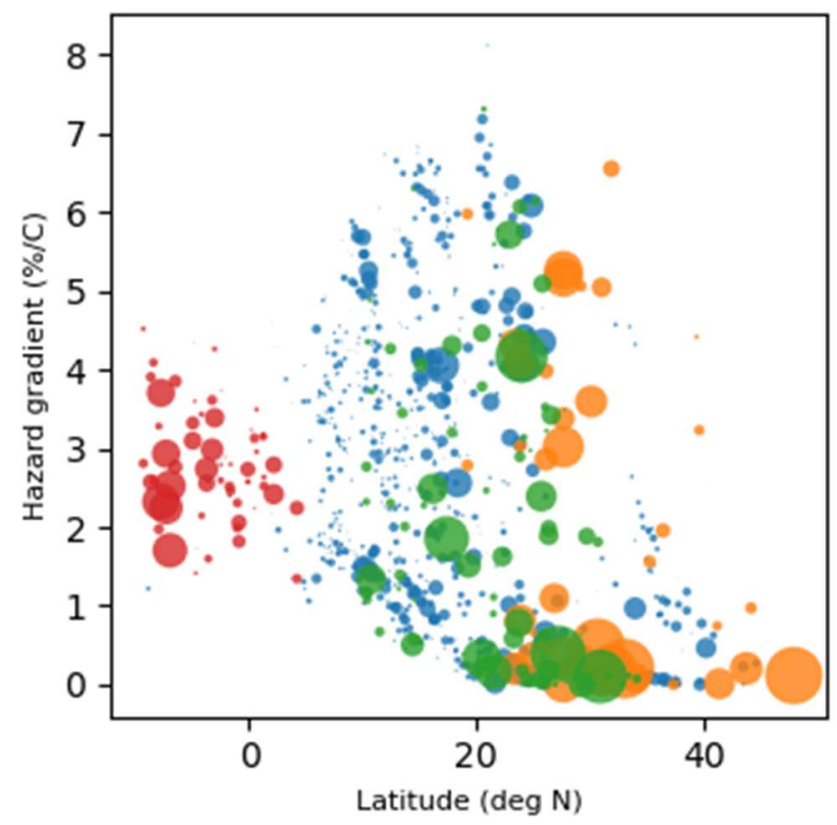

Supplementary Figure 4: Same as Supplementary Figure 1, but using the HOTHAPS high-intensity labour impact metric. 


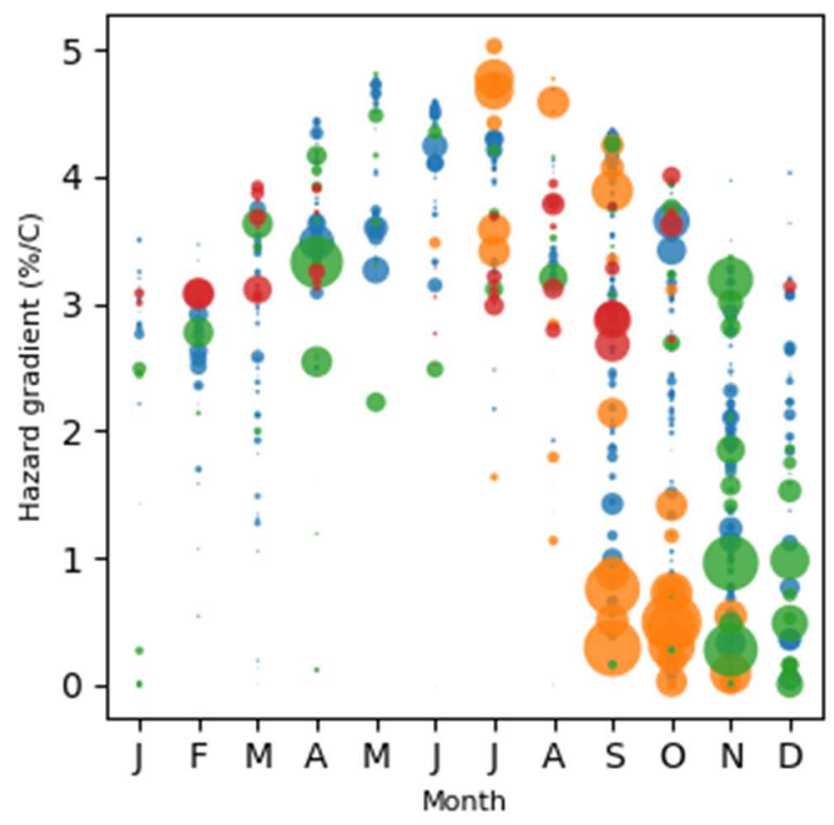

Supplementary Figure 5: As Figure 6c, but calculated from 3-hourly CMIP6 data.

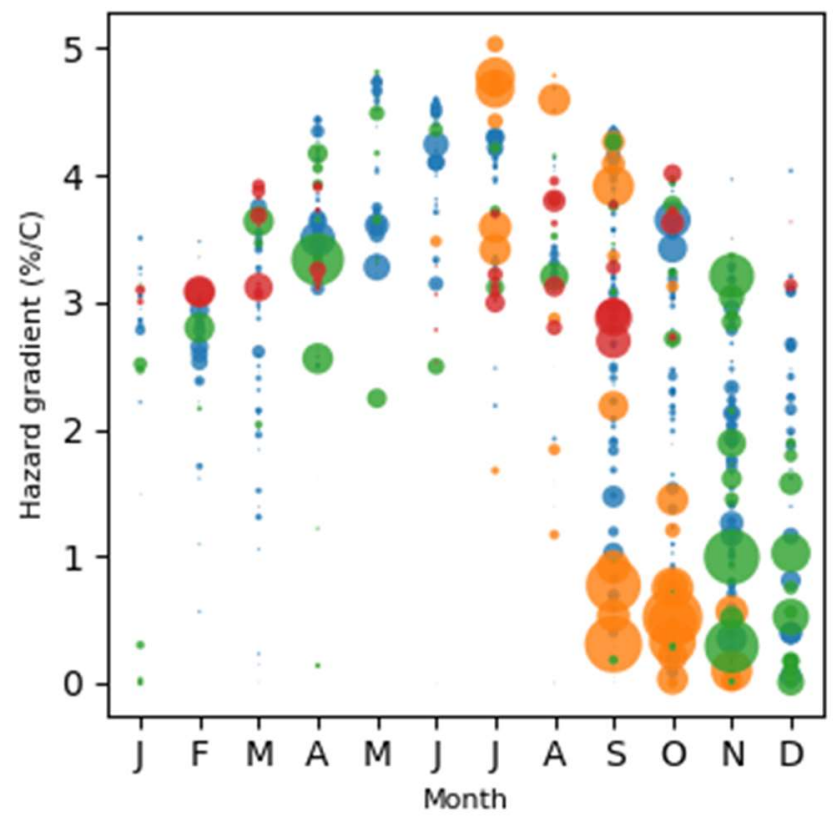

Supplementary Figure 6: Same as Supplementary Figure 5, but including radiation. 


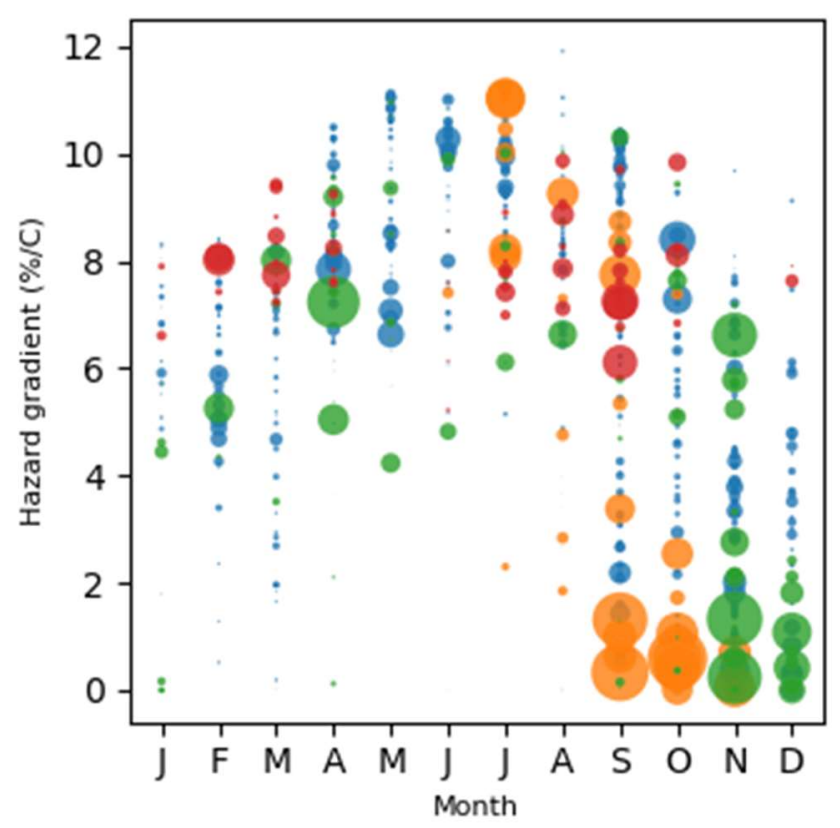

Supplementary Figure 7: Same as Supplementary Figure 5, but using the labour impact metric from Dunne, Stouffer and John (2013).

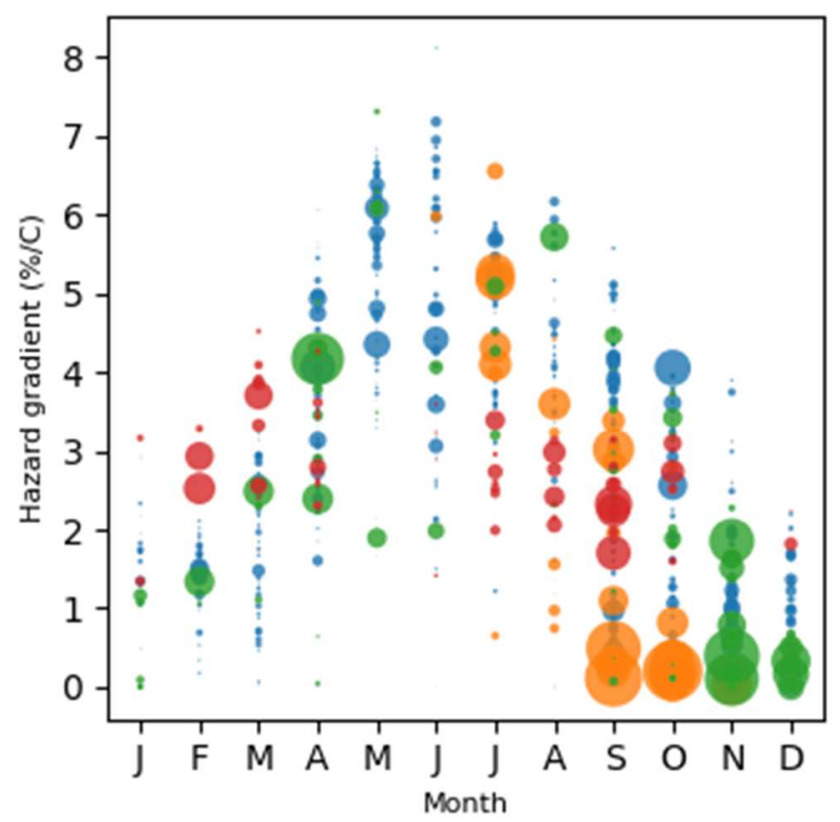

Supplementary Figure 8: Same as Supplementary Figure 5, but using the HOTHAPS high-intensity labour impact metric. 


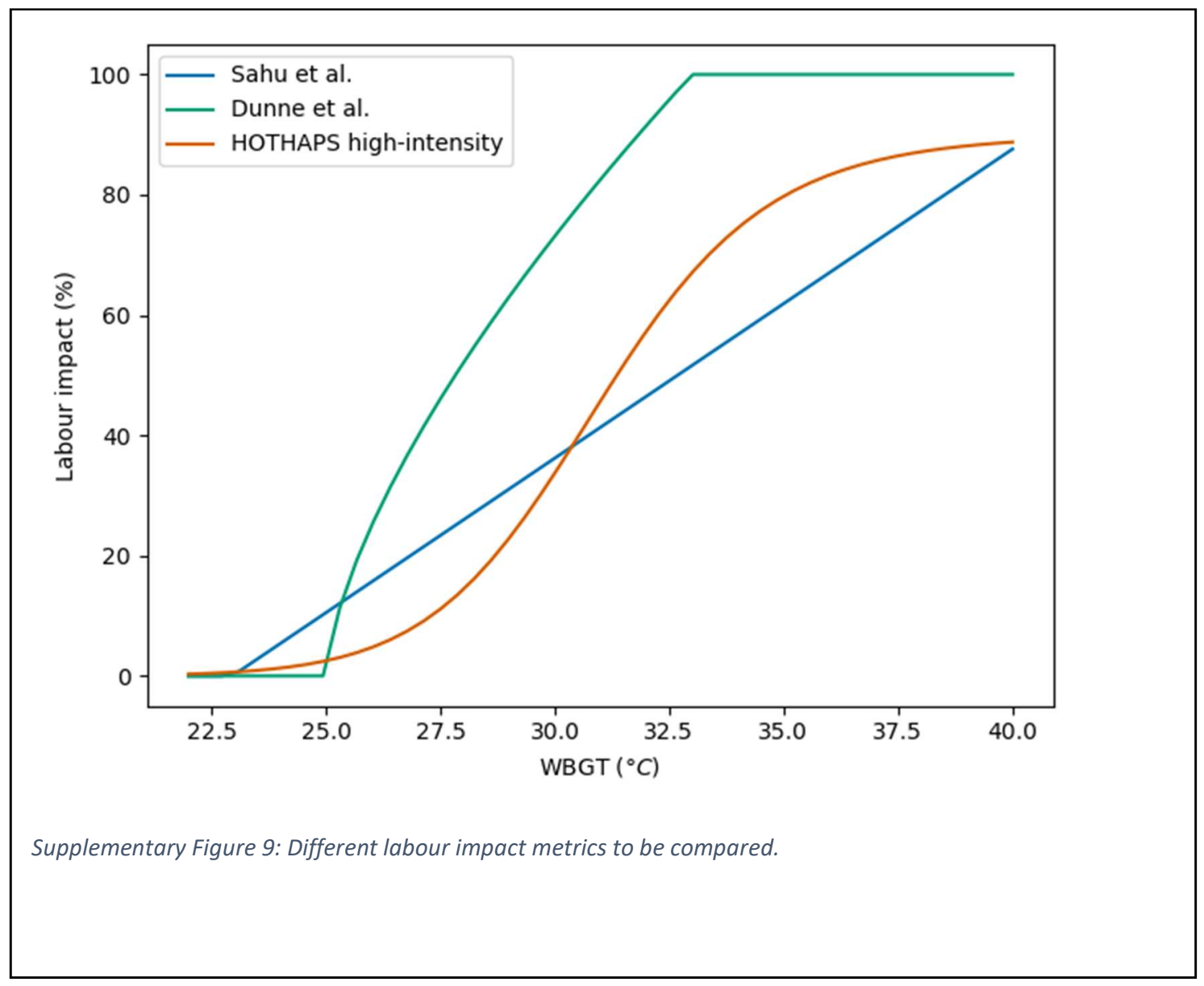




\author{
Supplementary Tables \\ Table of CMIP6 climate models used \\ ACCESS-CM2 \\ ACCESS-ESM1-5 \\ CanESM5 \\ FGOALS-g3 \\ GFDL-CM4 \\ HadGEM3-GC31-LL \\ INM-CM4-8 \\ INM-CM5-0 \\ MIROC6 \\ MPI-ESM1-2-HR \\ MPI-ESM1-2-LR \\ MRI-ESM2-0 \\ NorESM2-MM \\ UKESM1-0-LL
}

Table of CMIP6 data citations

Centre

Model

CAS

FGOALS-g3

CAS

FGOALS-g3

cCCma

CanESM5

cCCma

CanESM5

cCCma

CanESM5 $\operatorname{ssp} 370$

$\operatorname{ssp} 119$

ssp126

Experiment Citation

Li, L. (2019). CAS FGOALS-g3 model output prepared for CMIP6 CMIP historical. v20190826. Earth System Grid Federation. https://doi.org/10.22033/ESGF/CMIP6.3356 Li, L. (2019). CAS FGOALS-g3 model output prepared for CMIP6 ScenarioMIP ssp370. v20190820. Earth System Grid Federation.

https://doi.org/10.22033/ESGF/CMIP6.3480

Swart, N.C., Cole, J.N.S., Kharin, V.V., Lazare, M., Scinocca, J.F., Gillett, N.P., Anstey, J., Arora, V., Christian, J.R., Jiao, Y., Lee, W.G., Majaess, F., Saenko, O.A., Seiler, C., Seinen, C., Shao, A., Solheim, L., von Salzen, K., Yang, D., Winter, B., Sigmond, M. (2019). CCCma CanESM5 model output prepared for CMIP6 CMIP historical. v20190429. Earth System Grid Federation. https://doi.org/10.22033/ESGF/CMIP6.3610 Swart, N.C., Cole, J.N.S., Kharin, V.V., Lazare, M., Scinocca, J.F., Gillett, N.P., Anstey, J., Arora, V., Christian, J.R., Jiao, Y., Lee, W.G., Majaess, F., Saenko, O.A., Seiler, C., Seinen, C., Shao, A., Solheim, L., von Salzen, K., Yang, D., Winter, B., Sigmond, M. (2019). CCCma CanESM5 model output prepared for CMIP6 ScenarioMIP ssp119. v20190429. Earth System Grid Federation. https://doi.org/10.22033/ESGF/CMIP6.3682 Swart, N.C., Cole, J.N.S., Kharin, V.V., Lazare, M., Scinocca, J.F., Gillett, N.P., Anstey, J., Arora, V., Christian, J.R., Jiao, Y., Lee, W.G., Majaess, F., Saenko, O.A., Seiler, C., Seinen, C., Shao, A., Solheim, L., von Salzen, K., Yang, D., Winter, B., Sigmond, M. (2019). CCCma CanESM5 model output prepared for CMIP6 
ScenarioMIP ssp126. v20190429. Earth System Grid

Federation. https://doi.org/10.22033/ESGF/CMIP6.3683

cCCma

CanESM5

$\operatorname{ssp} 245$

CCCma

CanESM5

$\operatorname{ssp} 370$

cCCma

CanESM5

CCCma

CanESM5

$\operatorname{ssp} 460$

ssp534-

cCCma

over
Swart, N.C., Cole, J.N.S., Kharin, V.V., Lazare, M., Scinocca, J.F., Gillett, N.P., Anstey, J., Arora, V., Christian, J.R., Jiao, Y., Lee, W.G., Majaess, F., Saenko, O.A., Seiler, C., Seinen, C., Shao, A., Solheim, L., von Salzen, K., Yang, D., Winter, B., Sigmond, M. (2019). CCCma CanESM5 model output prepared for CMIP6 ScenarioMIP ssp245. v20190429. Earth System Grid Federation. https://doi.org/10.22033/ESGF/CMIP6.3685 Swart, N.C., Cole, J.N.S., Kharin, V.V., Lazare, M., Scinocca, J.F., Gillett, N.P., Anstey, J., Arora, V., Christian, J.R., Jiao, Y., Lee, W.G., Majaess, F., Saenko, O.A., Seiler, C., Seinen, C., Shao, A., Solheim, L., von Salzen, K., Yang, D., Winter, B., Sigmond, M. (2019). CCCma CanESM5 model output prepared for CMIP6 ScenarioMIP ssp370. v20190429. Earth System Grid Federation. https://doi.org/10.22033/ESGF/CMIP6.3690 Swart, N.C., Cole, J.N.S., Kharin, V.V., Lazare, M., Scinocca, J.F., Gillett, N.P., Anstey, J., Arora, V., Christian, J.R., Jiao, Y., Lee, W.G., Majaess, F., Saenko, O.A., Seiler, C., Seinen, C., Shao, A., Solheim, L., von Salzen, K., Yang, D., Winter, B., Sigmond, M. (2019). CCCma CanESM5 model output prepared for CMIP6 ScenarioMIP ssp434. v20190429. Earth System Grid Federation. https://doi.org/10.22033/ESGF/CMIP6.3692 Swart, N.C., Cole, J.N.S., Kharin, V.V., Lazare, M., Scinocca, J.F., Gillett, N.P., Anstey, J., Arora, V., Christian, J.R., Jiao, Y., Lee, W.G., Majaess, F., Saenko, O.A., Seiler, C., Seinen, C., Shao, A., Solheim, L., von Salzen, K., Yang, D., Winter, B., Sigmond, M. (2019). CCCma CanESM5 model output prepared for CMIP6 ScenarioMIP ssp460. v20190429. Earth System Grid Federation. https://doi.org/10.22033/ESGF/CMIP6.3693 Swart, N.C., Cole, J.N.S., Kharin, V.V., Lazare, M., Scinocca, J.F., Gillett, N.P., Anstey, J., Arora, V., Christian, J.R., Jiao, Y., Lee, W.G., Majaess, F., Saenko, O.A., Seiler, C., Seinen, C., Shao, A., Solheim, L., von Salzen, K., Yang, D., Winter, B., Sigmond, M. (2019). CCCma CanESM5 model output prepared for CMIP6 ScenarioMIP ssp534-over. v20190429. Earth System Grid Federation. https://doi.org/10.22033/ESGF/CMIP6.3694 
cccma

CNRM-

CERFACS

CNRM-

CERFACS

CNRM-

CERFACS

CNRM-

CERFACS

CNRM-

CERFACS

CSIRO

CSIRO

CSIRO
ACCESS-ESM1-5 ssp126

CanESM5

CNRM-CM6-1 historical

CNRM-CM6-1 ssp126

CNRM-CM6-1 ssp245

CNRM-CM6-1 ssp370

CNRM-CM6-1 ssp585

ACCESS-ESM1-5 historical

ACCESS-ESM1-5 ssp245
Swart, N.C., Cole, J.N.S., Kharin, V.V., Lazare, M., Scinocca, J.F., Gillett, N.P., Anstey, J., Arora, V., Christian, J.R., Jiao, Y., Lee, W.G., Majaess, F., Saenko, O.A., Seiler, C., Seinen, C., Shao, A., Solheim, L., von Salzen, K., Yang, D., Winter, B., Sigmond, M. (2019). CCCma CanESM5 model output prepared for CMIP6 ScenarioMIP ssp585. v20190429. Earth System Grid Federation. https://doi.org/10.22033/ESGF/CMIP6.3696 Voldoire, A. (2018). CNRM-CERFACS CNRM-CM6-1 model output prepared for CMIP6 CMIP historical. v20180917. Earth System Grid Federation. https://doi.org/10.22033/ESGF/CMIP6.4066 Voldoire, A. (2019). CNRM-CERFACS CNRM-CM6-1 model output prepared for CMIP6 ScenarioMIP ssp126. v20190219. Earth System Grid Federation. https://doi.org/10.22033/ESGF/CMIP6.4184 Voldoire, A. (2019). CNRM-CERFACS CNRM-CM6-1 model output prepared for CMIP6 ScenarioMIP ssp245. v20190219. Earth System Grid Federation. https://doi.org/10.22033/ESGF/CMIP6.4189 Voldoire, A. (2019). CNRM-CERFACS CNRM-CM6-1 model output prepared for CMIP6 ScenarioMIP ssp370. v20190219. Earth System Grid Federation. https://doi.org/10.22033/ESGF/CMIP6.4197 Voldoire, A. (2019). CNRM-CERFACS CNRM-CM6-1 model output prepared for CMIP6 ScenarioMIP ssp585. v20190219. Earth System Grid Federation. https://doi.org/10.22033/ESGF/CMIP6.4224 Ziehn, T., Chamberlain, M., Lenton, A., Law, R., Bodman, R., Dix, M., Wang, Y., Dobrohotoff, P., Srbinovsky, J., Stevens, L., Vohralik, P., Mackallah, C., Sullivan, A., O'Farrell, S., Druken, K. (2019). CSIRO ACCESS-ESM1-5 model output prepared for CMIP6 CMIP historical. v20191115. Earth System Grid Federation. https://doi.org/10.22033/ESGF/CMIP6.4272 Ziehn, T., Chamberlain, M., Lenton, A., Law, R., Bodman, R., Dix, M., Wang, Y., Dobrohotoff, P., Srbinovsky, J., Stevens, L., Vohralik, P., Mackallah, C., Sullivan, A., O'Farrell, S., Druken, K. (2019). CSIRO ACCESS-ESM1-5 model output prepared for CMIP6 ScenarioMIP ssp126. v20191115. Earth System Grid Federation. https://doi.org/10.22033/ESGF/CMIP6.4320 Ziehn, T., Chamberlain, M., Lenton, A., Law, R., Bodman, R., Dix, M., Wang, Y., Dobrohotoff, P., Srbinovsky, J., Stevens, L., Vohralik, P., Mackallah, C., Sullivan, A., O'Farrell, S., Druken, K. (2019). CSIRO ACCESS-ESM1-5 model output prepared for CMIP6 ScenarioMIP ssp245. v20191115. Earth System Grid Federation. https://doi.org/10.22033/ESGF/CMIP6.4322 
CSIRO

CSIRO

CSIRO-ARCCSS

ACCESS-CM2

historical

CSIRO-ARCCSS ACCESS-CM2

CSIRO-ARCCSS
Ziehn, T., Chamberlain, M., Lenton, A., Law, R., Bodman, R., Dix, M., Wang, Y., Dobrohotoff, P., Srbinovsky, J., Stevens, L., Vohralik, P., Mackallah, C., Sullivan, A., O'Farrell, S., Druken, K. (2019). CSIRO ACCESS-ESM1-5 model output prepared for CMIP6 ScenarioMIP ssp370. v20191115. Earth System Grid Federation. https://doi.org/10.22033/ESGF/CMIP6.4324 Ziehn, T., Chamberlain, M., Lenton, A., Law, R., Bodman, R., Dix, M., Wang, Y., Dobrohotoff, P., Srbinovsky, J., Stevens, L., Vohralik, P., Mackallah, C., Sullivan, A., O'Farrell, S., Druken, K. (2019). CSIRO ACCESS-ESM1-5 model output prepared for CMIP6 ScenarioMIP ssp585. v20191115. Earth System Grid Federation. https://doi.org/10.22033/ESGF/CMIP6.4333 Dix, M., Bi, D., Dobrohotoff, P., Fiedler, R., Harman, I., Law, R., Mackallah, C., Marsland, S., O'Farrell, S., Rashid, H., Srbinovsky, J., Sullivan, A., Trenham, C., Vohralik, P., Watterson, I., Williams, G., Woodhouse, M., Bodman, R., Dias, F.B., Domingues, C., Hannah, N., Heerdegen, A., Savita, A., Wales, S., Allen, C., Druken, K., Evans, B., Richards, C., Ridzwan, S.M., Roberts, D., Smillie, J., Snow, K., Ward, M., Yang, R. (2019). CSIRO-ARCCSS ACCESS-CM2 model output prepared for CMIP6 CMIP historical. v20191108. Earth System Grid Federation. https://doi.org/10.22033/ESGF/CMIP6.4271

Dix, M., Bi, D., Dobrohotoff, P., Fiedler, R., Harman, I. Law, R., Mackallah, C., Marsland, S., O'Farrell, S., Rashid, H., Srbinovsky, J., Sullivan, A., Trenham, C., Vohralik, P., Watterson, I., Williams, G., Woodhouse, M., Bodman, R., Dias, F.B., Domingues, C., Hannah, N., Heerdegen, A., Savita, A., Wales, S., Allen, C., Druken, K., Evans, B., Richards, C., Ridzwan, S.M., Roberts, D., Smillie, J., Snow, K., Ward, M., Yang, R. (2019). CSIRO-ARCCSS ACCESS-CM2 model output prepared for CMIP6 ScenarioMIP ssp126. v20191108. Earth System Grid Federation. https://doi.org/10.22033/ESGF/CMIP6.4319 Dix, M., Bi, D., Dobrohotoff, P., Fiedler, R., Harman, I., Law, R., Mackallah, C., Marsland, S., O'Farrell, S., Rashid, H., Srbinovsky, J., Sullivan, A., Trenham, C., Vohralik, P., Watterson, I., Williams, G., Woodhouse, M., Bodman, R., Dias, F.B., Domingues, C., Hannah, N., Heerdegen, A., Savita, A., Wales, S., Allen, C., Druken, K., Evans, B., Richards, C., Ridzwan, S.M., Roberts, D., Smillie, J., Snow, K., Ward, M., Yang, R. (2019). CSIRO-ARCCSS ACCESS-CM2 model output prepared for CMIP6 ScenarioMIP ssp245. v20191108. Earth System Grid Federation. https://doi.org/10.22033/ESGF/CMIP6.4321 
CSIRO-ARCCSS ACCESS-CM2 $\quad$ ssp370

\section{CSIRO-ARCCSS}

ACCESS-CM2

$\operatorname{ssp} 585$

DKRZ

MPI-ESM1-2-HR

ssp126

DKRZ
Dix, M., Bi, D., Dobrohotoff, P., Fiedler, R., Harman, I., Law, R., Mackallah, C., Marsland, S., O'Farrell, S., Rashid, H., Srbinovsky, J., Sullivan, A., Trenham, C., Vohralik, P., Watterson, I., Williams, G., Woodhouse, M., Bodman, R., Dias, F.B., Domingues, C., Hannah, N., Heerdegen, A., Savita, A., Wales, S., Allen, C., Druken, K., Evans, B., Richards, C., Ridzwan, S.M., Roberts, D., Smillie, J., Snow, K., Ward, M., Yang, R. (2019). CSIRO-ARCCSS ACCESS-CM2 model output prepared for CMIP6 ScenarioMIP ssp370. v20191108. Earth System Grid Federation. https://doi.org/10.22033/ESGF/CMIP6.4323 Dix, M., Bi, D., Dobrohotoff, P., Fiedler, R., Harman, I., Law, R., Mackallah, C., Marsland, S., O'Farrell, S., Rashid, H., Srbinovsky, J., Sullivan, A., Trenham, C., Vohralik, P., Watterson, I., Williams, G., Woodhouse, M., Bodman, R., Dias, F.B., Domingues, C., Hannah, N., Heerdegen, A., Savita, A., Wales, S., Allen, C., Druken, K., Evans, B., Richards, C., Ridzwan, S.M., Roberts, D., Smillie, J., Snow, K., Ward, M., Yang, R. (2019). CSIRO-ARCCSS ACCESS-CM2 model output prepared for CMIP6 ScenarioMIP ssp585. v20191108. Earth System Grid Federation. https://doi.org/10.22033/ESGF/CMIP6.4332 Schupfner, M., Wieners, K.H., Wachsmann, F., Steger, C., Bittner, M., Jungclaus, J., FrÃ $1 / 4 h$, B., Pankatz, K., Giorgetta, M., Reick, C., Legutke, S., Esch, M., Gayler, V., Haak, H., de Vrese, P., Raddatz, T., Mauritsen, T., von Storch, J.S., Behrens, J., Brovkin, V., Claussen, M., Crueger, T., Fast, I., Fiedler, S., Hagemann, S., Hohenegger, C., Jahns, T., Kloster, S., Kinne, S., Lasslop, G., Kornblueh, L., Marotzke, J., Matei, D., Meraner, K., Mikolajewicz, U., Modali, K., MÃ/4ller, W., Nabel, J., Notz, D., Peters, K., Pincus, R., Pohlmann, H., Pongratz, J., Rast, S., Schmidt, H., Schnur, R., Schulzweida, U., Six, K., Stevens, B., Voigt, A., Roeckner, E. (2019). DKRZ MPIESM1-2-HR model output prepared for CMIP6 ScenarioMIP ssp126. v20190710. Earth System Grid Federation. https://doi.org/10.22033/ESGF/CMIP6.4397 Schupfner, M., Wieners, K.H., Wachsmann, F., Steger, C., Bittner, M., Jungclaus, J., FrÃ²/4h, B., Pankatz, K., Giorgetta, M., Reick, C., Legutke, S., Esch, M., Gayler, V., Haak, H., de Vrese, P., Raddatz, T., Mauritsen, T., von Storch, J.S., Behrens, J., Brovkin, V., Claussen, M., Crueger, T., Fast, I., Fiedler, S., Hagemann, S., Hohenegger, C., Jahns, T., Kloster, S., Kinne, S., Lasslop, G., Kornblueh, L., Marotzke, J., Matei, D., Meraner, K., Mikolajewicz, U., Modali, K., MÃ¹/4ller, W., Nabel, J., Notz, D., Peters, K., Pincus, R., Pohlmann, H., Pongratz, J., Rast, S., Schmidt, H., Schnur, R., Schulzweida, U., Six, K., Stevens, B., Voigt, A., Roeckner, E. (2019). DKRZ MPIESM1-2-HR model output prepared for CMIP6 
ScenarioMIP ssp245. v20190710. Earth System Grid Federation. https://doi.org/10.22033/ESGF/CMIP6.4398
Schupfner, M., Wieners, K.H., Wachsmann, F., Steger, C., Bittner, M., Jungclaus, J., FrÃ²/4h, B., Pankatz, K., Giorgetta, M., Reick, C., Legutke, S., Esch, M., Gayler, V., Haak, H., de Vrese, P., Raddatz, T., Mauritsen, T., von Storch, J.S., Behrens, J., Brovkin, V., Claussen, M., Crueger, T., Fast, I., Fiedler, S., Hagemann, S., Hohenegger, C., Jahns, T., Kloster, S., Kinne, S., Lasslop, G., Kornblueh, L., Marotzke, J., Matei, D., Meraner, K., Mikolajewicz, U., Modali, K., MÃ̄1/4ller, W., Nabel, J., Notz, D., Peters, K., Pincus, R., Pohlmann, H., Pongratz, J., Rast, S., Schmidt, H., Schnur, R., Schulzweida, U., Six, K., Stevens, B., Voigt, A., Roeckner, E. (2019). DKRZ MPIESM1-2-HR model output prepared for CMIP6 ScenarioMIP ssp370. v20190710. Earth System Grid Federation. https://doi.org/10.22033/ESGF/CMIP6.4399 Schupfner, M., Wieners, K.H., Wachsmann, F., Steger, C., Bittner, M., Jungclaus, J., FrÃ²/4h, B., Pankatz, K., Giorgetta, M., Reick, C., Legutke, S., Esch, M., Gayler, V., Haak, H., de Vrese, P., Raddatz, T., Mauritsen, T., von Storch, J.S., Behrens, J., Brovkin, V., Claussen, M., Crueger, T., Fast, I., Fiedler, S., Hagemann, S., Hohenegger, C., Jahns, T., Kloster, S., Kinne, S., Lasslop, G., Kornblueh, L., Marotzke, J., Matei, D., Meraner, K., Mikolajewicz, U., Modali, K., MÃ̄/1ller, W., Nabel, J., Notz, D., Peters, K., Pincus, R., Pohlmann, H., Pongratz, J., Rast, S., Schmidt, H., Schnur, R., Schulzweida, U., Six, K., Stevens, B., Voigt, A., Roeckner, E. (2019). DKRZ MPIESM1-2-HR model output prepared for CMIP6 ScenarioMIP ssp585. v20190710. Earth System Grid Federation. https://doi.org/10.22033/ESGF/CMIP6.4403 Volodin, E., Mortikov, E., Gritsun, A., Lykossov, V., Galin, V., Diansky, N., Gusev, A., Kostrykin, S., lakovlev, N., Shestakova, A., Emelina, S. (2019). INM INM-CM4-8 model output prepared for CMIP6 CMIP historical. v20190530. Earth System Grid Federation. https://doi.org/10.22033/ESGF/CMIP6.5069

Volodin, E., Mortikov, E., Gritsun, A., Lykossov, V., Galin, V., Diansky, N., Gusev, A., Kostrykin, S., lakovlev, N., Shestakova, A., Emelina, S. (2019). INM INM-CM4-8 model output prepared for CMIP6 ScenarioMIP ssp126. 
v20190603. Earth System Grid Federation.

https://doi.org/10.22033/ESGF/CMIP6.12325

INM

INM

INM

INM

INM

INM

MIROC

MIROC

MIROC
INM-CM5-0

MIROC6

MIROC6

ssp119

INM-CM4-8

$\operatorname{ssp} 585$

historical

ssp126

$\operatorname{ssp} 370$

$\operatorname{ssp} 585$

historical

MIROC6
Volodin, E., Mortikov, E., Gritsun, A., Lykossov, V., Galin, V., Diansky, N., Gusev, A., Kostrykin, S., lakovlev, N., Shestakova, A., Emelina, S. (2019). INM INM-CM4-8 model output prepared for CMIP6 ScenarioMIP ssp370. v20190603. Earth System Grid Federation. https://doi.org/10.22033/ESGF/CMIP6.12329 Volodin, E., Mortikov, E., Gritsun, A., Lykossov, V., Galin, V., Diansky, N., Gusev, A., Kostrykin, S., lakovlev, N., Shestakova, A., Emelina, S. (2019). INM INM-CM4-8 model output prepared for CMIP6 ScenarioMIP ssp585. v20190603. Earth System Grid Federation. https://doi.org/10.22033/ESGF/CMIP6.12337 Volodin, E., Mortikov, E., Gritsun, A., Lykossov, V., Galin, V., Diansky, N., Gusev, A., Kostrykin, S., lakovlev, N., Shestakova, A., Emelina, S. (2019). INM INM-CM5-0 model output prepared for CMIP6 CMIP historical. v20190610. Earth System Grid Federation. https://doi.org/10.22033/ESGF/CMIP6.5070 Volodin, E., Mortikov, E., Gritsun, A., Lykossov, V., Galin, V., Diansky, N., Gusev, A., Kostrykin, S., lakovlev, N., Shestakova, A., Emelina, S. (2019). INM INM-CM5-0 model output prepared for CMIP6 ScenarioMIP ssp126. v20190619. Earth System Grid Federation. https://doi.org/10.22033/ESGF/CMIP6.12326 Volodin, E., Mortikov, E., Gritsun, A., Lykossov, V., Galin, V., Diansky, N., Gusev, A., Kostrykin, S., lakovlev, N., Shestakova, A., Emelina, S. (2019). INM INM-CM5-0 model output prepared for CMIP6 ScenarioMIP ssp370. v20190618. Earth System Grid Federation. https://doi.org/10.22033/ESGF/CMIP6.12330 Volodin, E., Mortikov, E., Gritsun, A., Lykossov, V., Galin, V., Diansky, N., Gusev, A., Kostrykin, S., lakovlev, N., Shestakova, A., Emelina, S. (2019). INM INM-CM5-0 model output prepared for CMIP6 ScenarioMIP ssp585. v20190724. Earth System Grid Federation. https://doi.org/10.22033/ESGF/CMIP6.12338 Tatebe, H., Watanabe, M. (2018). MIROC MIROC6 model output prepared for CMIP6 CMIP historical. v20191016. Earth System Grid Federation. https://doi.org/10.22033/ESGF/CMIP6.5603 Shiogama, H., Abe, M., Tatebe, H. (2019). MIROC MIROC6 model output prepared for CMIP6 ScenarioMIP ssp119. v20191016. Earth System Grid Federation. https://doi.org/10.22033/ESGF/CMIP6.5741
Shiogama, H., Abe, M., Tatebe, H. (2019). MIROC MIROC6 model output prepared for CMIP6 ScenarioMIP 
MIROC

MIROC6

$\operatorname{ssp} 370$

MIROC

MIROC6

$\operatorname{ssp} 434$

MIROC

MIROC

MIROC

$\mathrm{MOHC}$

$\mathrm{MOHC}$

$\mathrm{MOHC}$

$\mathrm{MOHC}$

$\mathrm{MOHC}$

$\mathrm{MOHC}$
MIROC6

MIROC6

HadGEM3-GC31LL

HadGEM3-GC31-

LL

HadGEM3-GC31-

LL

HadGEM3-GC31-

LL

ssp585

UKESM1-0-LL historical over

historical

$\operatorname{ssp} 245$ ssp126. v20191016. Earth System Grid Federation https://doi.org/10.22033/ESGF/CMIP6.5743

Shiogama, H., Abe, M., Tatebe, H. (2019). MIROC MIROC6 model output prepared for CMIP6 ScenarioMIP ssp370. v20191016. Earth System Grid Federation. https://doi.org/10.22033/ESGF/CMIP6.5752 Shiogama, H., Abe, M., Tatebe, H. (2019). MIROC MIROC6 model output prepared for CMIP6 ScenarioMIP ssp434. v20191016. Earth System Grid Federation. https://doi.org/10.22033/ESGF/CMIP6.5764 Shiogama, H., Abe, M., Tatebe, H. (2019). MIROC MIROC6 model output prepared for CMIP6 ScenarioMIP ssp460. v20191016. Earth System Grid Federation. https://doi.org/10.22033/ESGF/CMIP6.5766 Shiogama, H., Abe, M., Tatebe, H. (2019). MIROC MIROC6 model output prepared for CMIP6 ScenarioMIP ssp534- ssp534-over. v20191016. Earth System Grid Federation. https://doi.org/10.22033/ESGF/CMIP6.5768 Shiogama, H., Abe, M., Tatebe, H. (2019). MIROC MIROC6 model output prepared for CMIP6 ScenarioMIP ssp585. v20191016. Earth System Grid Federation. https://doi.org/10.22033/ESGF/CMIP6.5771 Ridley, J., Menary, M., Kuhlbrodt, T., Andrews, M., Andrews, T. (2019). MOHC HadGEM3-GC31-LL model output prepared for CMIP6 CMIP historical. v20190624. Earth System Grid Federation.

https://doi.org/10.22033/ESGF/CMIP6.6109

Good, P. (2020). MOHC HadGEM3-GC31-LL model output prepared for CMIP6 ScenarioMIP ssp126. v20200114. Earth System Grid Federation. https://doi.org/10.22033/ESGF/CMIP6.10849 Good, P. (2019). MOHC HadGEM3-GC31-LL model output prepared for CMIP6 ScenarioMIP ssp245. v20190908. Earth System Grid Federation. https://doi.org/10.22033/ESGF/CMIP6.10851 Good, P. (2020). MOHC HadGEM3-GC31-LL model output prepared for CMIP6 ScenarioMIP ssp585. v20200114. Earth System Grid Federation. https://doi.org/10.22033/ESGF/CMIP6.10901 Tang, Y., Rumbold, S., Ellis, R., Kelley, D., Mulcahy, J., Sellar, A., Walton, J., Jones, C. (2019). MOHC UKESM1-0LL model output prepared for CMIP6 CMIP historical. v20191209. Earth System Grid Federation. https://doi.org/10.22033/ESGF/CMIP6.6113 Good, P., Sellar, A., Tang, Y., Rumbold, S., Ellis, R., Kelley, D., Kuhlbrodt, T. (2019). MOHC UKESM1-0-LL model output prepared for CMIP6 ScenarioMIP ssp119. v20190830. Earth System Grid Federation. https://doi.org/10.22033/ESGF/CMIP6.6329 
MOHC

UKESM1-0-LL ssp126

MOHC

UKESM1-0-LL ssp245

MOHC

UKESM1-0-LL

ssp370

MOHC

UKESM1-0-LL

ssp434

$\mathrm{MOHC}$

UKESM1-0-LL

ssp534-

over

MOHC

UKESM1-0-LL

ssp585

MPI-M
Good, P., Sellar, A., Tang, Y., Rumbold, S., Ellis, R., Kelley, D., Kuhlbrodt, T. (2019). MOHC UKESM1-0-LL model output prepared for CMIP6 ScenarioMIP ssp126. v20190708. Earth System Grid Federation.

https://doi.org/10.22033/ESGF/CMIP6.6333

Good, P., Sellar, A., Tang, Y., Rumbold, S., Ellis, R., Kelley, D., Kuhlbrodt, T. (2019). MOHC UKESM1-0-LL model output prepared for CMIP6 ScenarioMIP ssp245. v20190715. Earth System Grid Federation.

https://doi.org/10.22033/ESGF/CMIP6.6339

Good, P., Sellar, A., Tang, Y., Rumbold, S., Ellis, R., Kelley, D., Kuhlbrodt, T. (2019). MOHC UKESM1-0-LL model output prepared for CMIP6 ScenarioMIP ssp370. v20190726. Earth System Grid Federation.

https://doi.org/10.22033/ESGF/CMIP6.6347

Good, P., Sellar, A., Tang, Y., Rumbold, S., Ellis, R., Kelley, D., Kuhlbrodt, T. (2019). MOHC UKESM1-0-LL model output prepared for CMIP6 ScenarioMIP ssp434. v20190828. Earth System Grid Federation. https://doi.org/10.22033/ESGF/CMIP6.6389 Good, P., Sellar, A., Tang, Y., Rumbold, S., Ellis, R., Kelley, D., Kuhlbrodt, T. (2019). MOHC UKESM1-0-LL model output prepared for CMIP6 ScenarioMIP ssp534over. v20190830. Earth System Grid Federation. https://doi.org/10.22033/ESGF/CMIP6.6397 Good, P., Sellar, A., Tang, Y., Rumbold, S., Ellis, R., Kelley, D., Kuhlbrodt, T. (2019). MOHC UKESM1-0-LL model output prepared for CMIP6 ScenarioMIP ssp585. v20190726. Earth System Grid Federation. https://doi.org/10.22033/ESGF/CMIP6.6405 Jungclaus, J., Bittner, M., Wieners, K.H., Wachsmann, F., Schupfner, M., Legutke, S., Giorgetta, M., Reick, C., Gayler, V., Haak, H., de Vrese, P., Raddatz, T., Esch, M., Mauritsen, T., von Storch, J.S., Behrens, J., Brovkin, V., Claussen, M., Crueger, T., Fast, I., Fiedler, S., Hagemann, S., Hohenegger, C., Jahns, T., Kloster, S., Kinne, S., Lasslop, G., Kornblueh, L., Marotzke, J., Matei, D., Meraner, K., Mikolajewicz, U., Modali, K., MÃ̌lller, W., Nabel, J., Notz, D., Peters, K., Pincus, R., Pohlmann, H., Pongratz, J., Rast, S., Schmidt, H., Schnur, R., Schulzweida, U., Six, K., Stevens, B., Voigt, A., Roeckner, E. (2019). MPI-M MPI-ESM1-2-HR model output prepared for CMIP6 CMIP historical. v20190710. Earth System Grid Federation.

https://doi.org/10.22033/ESGF/CMIP6.6594 
Wieners, K.H., Giorgetta, M., Jungclaus, J., Reick, C., Esch, M., Bittner, M., Legutke, S., Schupfner, M., Wachsmann, F., Gayler, V., Haak, H., de Vrese, P., Raddatz, T., Mauritsen, T., von Storch, J.S., Behrens, J., Brovkin, V., Claussen, M., Crueger, T., Fast, I., Fiedler, S., Hagemann, S., Hohenegger, C., Jahns, T., Kloster, S., Kinne, S., Lasslop, G., Kornblueh, L., Marotzke, J., Matei, D., Meraner, K., Mikolajewicz, U., Modali, K., MÃ̄1/4ller, W., Nabel, J., Notz, D., Peters, K., Pincus, R., Pohlmann, H., Pongratz, J., Rast, S., Schmidt, H., Schnur, R., Schulzweida, U., Six, K., Stevens, B., Voigt, A., Roeckner, E. (2019). MPI-M MPI-ESM1-2-LR model output prepared for CMIP6 CMIP historical. v20190710. Earth System Grid Federation. https://doi.org/10.22033/ESGF/CMIP6.6595 Wieners, K.H., Giorgetta, M., Jungclaus, J., Reick, C., Esch, M., Bittner, M., Gayler, V., Haak, H., de Vrese, P., Raddatz, T., Mauritsen, T., von Storch, J.S., Behrens, J., Brovkin, V., Claussen, M., Crueger, T., Fast, I., Fiedler, S., Hagemann, S., Hohenegger, C., Jahns, T., Kloster, S., Kinne, S., Lasslop, G., Kornblueh, L., Marotzke, J., Matei, D., Meraner, K., Mikolajewicz, U., Modali, K., MÃ²/4ller, W., Nabel, J., Notz, D., Peters, K., Pincus, R., Pohlmann, H., Pongratz, J., Rast, S., Schmidt, H., Schnur, R., Schulzweida, U., Six, K., Stevens, B., Voigt, A., Roeckner, E. (2019). MPI-M MPI-ESM1-2-LR model output prepared for CMIP6 ScenarioMIP ssp126. v20190710. Earth System Grid Federation. https://doi.org/10.22033/ESGF/CMIP6.6690 Wieners, K.H., Giorgetta, M., Jungclaus, J., Reick, C., Esch, M., Bittner, M., Gayler, V., Haak, H., de Vrese, P., Raddatz, T., Mauritsen, T., von Storch, J.S., Behrens, J., Brovkin, V., Claussen, M., Crueger, T., Fast, I., Fiedler, S., Hagemann, S., Hohenegger, C., Jahns, T., Kloster, S., Kinne, S., Lasslop, G., Kornblueh, L., Marotzke, J., Matei, D., Meraner, K., Mikolajewicz, U., Modali, K., MÃ²/4ler, W., Nabel, J., Notz, D., Peters, K., Pincus, R., Pohlmann, H., Pongratz, J., Rast, S., Schmidt, H., Schnur, R., Schulzweida, U., Six, K., Stevens, B., Voigt, A., Roeckner, E. (2019). MPI-M MPI-ESM1-2-LR model output prepared for CMIP6 ScenarioMIP ssp370. v20190710. Earth System Grid Federation. 
MPI-M

MRI

MRI

MRI

MRI

MRI
MRI-ESM2-0

$\operatorname{ssp} 245$

MPI-ESM1-2-LR ssp585

MRI-ESM2-0

MRI-ESM2-0

ssp119

MRI-ESM2-0

ssp126

$\operatorname{ssp} 370$
Wieners, K.H., Giorgetta, M., Jungclaus, J., Reick, C., Esch, M., Bittner, M., Gayler, V., Haak, H., de Vrese, P., Raddatz, T., Mauritsen, T., von Storch, J.S., Behrens, J., Brovkin, V., Claussen, M., Crueger, T., Fast, I., Fiedler, S., Hagemann, S., Hohenegger, C., Jahns, T., Kloster, S., Kinne, S., Lasslop, G., Kornblueh, L., Marotzke, J., Matei, D., Meraner, K., Mikolajewicz, U., Modali, K., MÃ̄1/4ler, W., Nabel, J., Notz, D., Peters, K., Pincus, R., Pohlmann, H., Pongratz, J., Rast, S., Schmidt, H., Schnur, R., Schulzweida, U., Six, K., Stevens, B., Voigt, A., Roeckner, E. (2019). MPI-M MPI-ESM1-2-LR model output prepared for CMIP6 ScenarioMIP ssp585. v20190710. Earth System Grid Federation. https://doi.org/10.22033/ESGF/CMIP6.6705 Yukimoto, S., Koshiro, T., Kawai, H., Oshima, N., Yoshida, K., Urakawa, S., Tsujino, H., Deushi, M., Tanaka, T., Hosaka, M., Yoshimura, H., Shindo, E., Mizuta, R., Ishii, M., Obata, A., Adachi, Y. (2019). MRI MRI-ESM2-0 model output prepared for CMIP6 CMIP historical. v20190603. Earth System Grid Federation. https://doi.org/10.22033/ESGF/CMIP6.6842 Yukimoto, S., Koshiro, T., Kawai, H., Oshima, N., Yoshida, K., Urakawa, S., Tsujino, H., Deushi, M., Tanaka, T., Hosaka, M., Yoshimura, H., Shindo, E., Mizuta, R., Ishii, M., Obata, A., Adachi, Y. (2019). MRI MRI-ESM2-0 model output prepared for CMIP6 ScenarioMIP ssp119. v20190603. Earth System Grid Federation. https://doi.org/10.22033/ESGF/CMIP6.6908 Yukimoto, S., Koshiro, T., Kawai, H., Oshima, N., Yoshida, K., Urakawa, S., Tsujino, H., Deushi, M., Tanaka, T., Hosaka, M., Yoshimura, H., Shindo, E., Mizuta, R., Ishii, M., Obata, A., Adachi, Y. (2019). MRI MRI-ESM2-0 model output prepared for CMIP6 ScenarioMIP ssp126. v20191108. Earth System Grid Federation. https://doi.org/10.22033/ESGF/CMIP6.6909 Yukimoto, S., Koshiro, T., Kawai, H., Oshima, N., Yoshida, K., Urakawa, S., Tsujino, H., Deushi, M., Tanaka, T., Hosaka, M., Yoshimura, H., Shindo, E., Mizuta, R., Ishii, M., Obata, A., Adachi, Y. (2019). MRI MRI-ESM2-0 model output prepared for CMIP6 ScenarioMIP ssp245. v20190603. Earth System Grid Federation. https://doi.org/10.22033/ESGF/CMIP6.6910 Yukimoto, S., Koshiro, T., Kawai, H., Oshima, N., Yoshida, K., Urakawa, S., Tsujino, H., Deushi, M., Tanaka, T., Hosaka, M., Yoshimura, H., Shindo, E., Mizuta, R., Ishii, M., Obata, A., Adachi, Y. (2019). MRI MRI-ESM2-0 model output prepared for CMIP6 ScenarioMIP ssp370. v20190603. Earth System Grid Federation. https://doi.org/10.22033/ESGF/CMIP6.6915 
MRI

MRI

MRI

NCC

NCC

NCC
NorESM2-MM ssp126

MRI-ESM2-0

MRI-ESM2-0

MRI-ESM2-0

$\operatorname{ssp} 585$

NorESM2-MM historical

NorESM2-MM ssp370
Yukimoto, S., Koshiro, T., Kawai, H., Oshima, N., Yoshida, K., Urakawa, S., Tsujino, H., Deushi, M., Tanaka, T., Hosaka, M., Yoshimura, H., Shindo, E., Mizuta, R., Ishii, M., Obata, A., Adachi, Y. (2019). MRI MRI-ESM2-0 model output prepared for CMIP6 ScenarioMIP ssp434. v20190603. Earth System Grid Federation. https://doi.org/10.22033/ESGF/CMIP6.6925 Yukimoto, S., Koshiro, T., Kawai, H., Oshima, N., Yoshida, K., Urakawa, S., Tsujino, H., Deushi, M., Tanaka, T., Hosaka, M., Yoshimura, H., Shindo, E., Mizuta, R., Ishii, M., Obata, A., Adachi, Y. (2019). MRI MRI-ESM2-0 model output prepared for CMIP6 ScenarioMIP ssp460. v20190603. Earth System Grid Federation. https://doi.org/10.22033/ESGF/CMIP6.6926 Yukimoto, S., Koshiro, T., Kawai, H., Oshima, N., Yoshida, K., Urakawa, S., Tsujino, H., Deushi, M., Tanaka, T., Hosaka, M., Yoshimura, H., Shindo, E., Mizuta, R., Ishii, M., Obata, A., Adachi, Y. (2019). MRI MRI-ESM2-0 model output prepared for CMIP6 ScenarioMIP ssp585. v20191108. Earth System Grid Federation. https://doi.org/10.22033/ESGF/CMIP6.6929

Bentsen, M., Olivi $\tilde{A}^{*}$, D.J.L., Seland, $\tilde{A}^{\sim}$., Toniazzo, T., Gjermundsen, A., Graff, L.S., Debernard, J.B., Gupta,

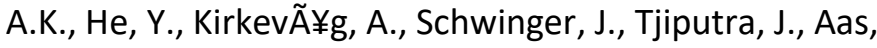
K.S., Bethke, I., Fan, Y., Griesfeller, J., Grini, A., Guo, C., Ilicak, M., Karset, I.H.H., Landgren, O.A., Liakka, J., Moseid, K.O., Nummelin, A., Spensberger, C., Tang, H., Zhang, Z., Heinze, C., Iversen, T., Schulz, M. (2019). NCC NorESM2-MM model output prepared for CMIP6 CMIP historical. v20191108. Earth System Grid Federation. https://doi.org/10.22033/ESGF/CMIP6.8040 Bentsen, M., Olivi ̃̃ “, D.J.L., Seland, Ã ., Toniazzo, T., Gjermundsen, A., Graff, L.S., Debernard, J.B., Gupta, A.K., He, Y., KirkevÃ $¥ g, A .$, Schwinger, J., Tjiputra, J., Aas, K.S., Bethke, I., Fan, Y., Griesfeller, J., Grini, A., Guo, C., Ilicak, M., Karset, I.H.H., Landgren, O.A., Liakka, J., Moseid, K.O., Nummelin, A., Spensberger, C., Tang, H., Zhang, Z., Heinze, C., Iversen, T., Schulz, M. (2019). NCC NorESM2-MM model output prepared for CMIP6 ScenarioMIP ssp126. v20191108. Earth System Grid Federation. https://doi.org/10.22033/ESGF/CMIP6.8250 Bentsen, M., OliviÃ *, D.J.L., Seland, Ã ., Toniazzo, T., Gjermundsen, A., Graff, L.S., Debernard, J.B., Gupta, A.K., He, Y., KirkevÃ $¥ g, A$., Schwinger, J., Tjiputra, J., Aas, K.S., Bethke, I., Fan, Y., Griesfeller, J., Grini, A., Guo, C., Ilicak, M., Karset, I.H.H., Landgren, O.A., Liakka, J., Moseid, K.O., Nummelin, A., Spensberger, C., Tang, H., Zhang, Z., Heinze, C., Iversen, T., Schulz, M. (2019). NCC NorESM2-MM model output prepared for CMIP6 ScenarioMIP ssp370. v20191108. Earth System Grid Federation. https://doi.org/10.22033/ESGF/CMIP6.8270 
NOAA-GFDL

GFDL-CM4

NOAA-GFDL

GFDL-CM4

$\operatorname{ssp} 245$

NOAA-GFDL
Guo, H., John, J.G., Blanton, C., McHugh, C., Nikonov, S., Radhakrishnan, A., Rand, K., Zadeh, N.T., Balaji, V., Durachta, J., Dupuis, C., Menzel, R., Robinson, T., Underwood, S., Vahlenkamp, H., Bushuk, M., Dunne, K.A., Dussin, R., Gauthier, P.P.G., Ginoux, P., Griffies, S.M., Hallberg, R., Harrison, M., Hurlin, W., Malyshev, S., Naik, V., Paulot, F., Paynter, D.J., Ploshay, J., Reichl, B.G., Schwarzkopf, D.M., Seman, C.J., Shao, A., Silvers, L., Wyman, B., Yan, X., Zeng, Y., Adcroft, A., Dunne, J.P., Held, I.M., Krasting, J.P., Horowitz, L.W., Milly, P.C.D., Shevliakova, E., Winton, M., Zhao, M., Zhang, R. (2018). NOAA-GFDL GFDL-CM4 model output prepared for CMIP6 CMIP historical. v20180701. Earth System Grid Federation. https://doi.org/10.22033/ESGF/CMIP6.8594 Guo, H., John, J.G., Blanton, C., McHugh, C., Nikonov, S., Radhakrishnan, A., Zadeh, N.T., Balaji, V., Durachta, J., Dupuis, C., Menzel, R., Robinson, T., Underwood, S., Vahlenkamp, H., Dunne, K.A., Gauthier, P.P.G., Ginoux, P., Griffies, S.M., Hallberg, R., Harrison, M., Hurlin, W., Lin, P., Malyshev, S., Naik, V., Paulot, F., Paynter, D.J., Ploshay, J., Schwarzkopf, D.M., Seman, C.J., Shao, A., Silvers, L., Wyman, B., Yan, X., Zeng, Y., Adcroft, A., Dunne, J.P., Held, I.M., Krasting, J.P., Horowitz, L.W., Milly, C., Shevliakova, E., Winton, M., Zhao, M., Zhang, R. (2018). NOAA-GFDL GFDL-CM4 model output prepared for CMIP6 ScenarioMIP ssp245. v20180701. Earth System Grid Federation. https://doi.org/10.22033/ESGF/CMIP6.9263 Guo, H., John, J.G., Blanton, C., McHugh, C., Nikonov, S., Radhakrishnan, A., Zadeh, N.T., Balaji, V., Durachta, J., Dupuis, C., Menzel, R., Robinson, T., Underwood, S., Vahlenkamp, H., Dunne, K.A., Gauthier, P.P.G., Ginoux, P., Griffies, S.M., Hallberg, R., Harrison, M., Hurlin, W., Lin, P., Malyshev, S., Naik, V., Paulot, F., Paynter, D.J., Ploshay, J., Schwarzkopf, D.M., Seman, C.J., Shao, A., Silvers, L., Wyman, B., Yan, X., Zeng, Y., Adcroft, A., Dunne, J.P., Held, I.M., Krasting, J.P., Horowitz, L.W., Milly, C., Shevliakova, E., Winton, M., Zhao, M., Zhang, R. (2018). NOAA-GFDL GFDL-CM4 model output prepared for CMIP6 ScenarioMIP ssp585. v20180701. Earth System Grid Federation. https://doi.org/10.22033/ESGF/CMIP6.9268 